\title{
Polar middle atmosphere temperature climatology from Rayleigh lidar measurements at ALOMAR $\left(69^{\circ} \mathrm{N}\right)$
}

\author{
A. Schöch ${ }^{1, *}$, G. Baumgarten ${ }^{1}$, and J. Fiedler ${ }^{1}$ \\ ${ }^{1}$ Leibniz-Institute of Atmospheric Physics, Kühlungsborn, Germany \\ *now at: Carl Zeiss SMT AG, Oberkochen, Germany
}

Received: 19 November 2007 - Revised: 6 April 2008 - Accepted: 29 April 2008 - Published: 13 June 2008

\begin{abstract}
Rayleigh lidar temperature profiles have been derived in the polar middle atmosphere from 834 measurements with the ALOMAR Rayleigh/Mie/Raman lidar $\left(69.3^{\circ} \mathrm{N}\right.$, $16.0^{\circ} \mathrm{E}$ ) in the years 1997-2005. Since our instrument is able to operate under full daylight conditions, the unique data set presented here extends over the entire year and covers the altitude region $30 \mathrm{~km}-85 \mathrm{~km}$ in winter and $30 \mathrm{~km}-65 \mathrm{~km}$ in summer. Comparisons of our lidar data set to reference atmospheres and ECMWF analyses show agreement within a few Kelvin in summer but in winter higher temperatures below $55 \mathrm{~km}$ and lower temperatures above by as much as $25 \mathrm{~K}$, due likely to superior resolution of stratospheric warming and associated mesospheric cooling events. We also present a temperature climatology for the entire lower and middle atmosphere at $69^{\circ} \mathrm{N}$ obtained from a combination of lidar measurements, falling sphere measurements and ECMWF analyses. Day to day temperature variability in the lidar data is found to be largest in winter and smallest in summer.
\end{abstract}

Keywords. Atmospheric composition and structure (Pressure, density, and temperature; Instruments and techniques) - Meteorology and atmospheric dynamics (Climatology)

\section{Introduction}

The polar middle atmosphere has received much attention because it harbours many different phenomena like polar stratospheric clouds, noctilucent clouds, stratospheric warmings, mesospheric inversion layers and gravity waves. During polar summer the mesopause region features the lowest temperatures occurring in the atmosphere falling to below $130 \mathrm{~K}$. The mesosphere/mesopause region has also been suggested to be a "miner's canary" of climate change (Thomas et al., 1989; von Zahn, 2003). Comprehensive tem-

Correspondence to: A. Schöch

(armin.schoech@web.de) perature measurements in the polar middle atmosphere during the whole year are an important contribution to increase our understanding of this part of the atmosphere.

The ALOMAR Rayleigh/Mie/Raman (RMR) lidar was installed on the island of Andøya $\left(69.28^{\circ} \mathrm{N}, 16.01^{\circ} \mathrm{E}\right)$ in Northern Norway in summer 1994. It has since been used to study middle atmosphere temperatures (von Zahn et al., 1998), noctilucent clouds (Baumgarten et al., 2002; Fiedler et al., 2003), polar stratospheric clouds (Fierli et al., 1998) and gravity waves (Schöch et al., 2004; Schöch, 2007).

Lidar temperature measurements at Andøya started about ten years before the installation of the RMR lidar with a $\mathrm{Na}$ resonance lidar (Fricke and von Zahn, 1985). It reported summer and winter temperatures from the altitude region $80 \mathrm{~km}-105 \mathrm{~km}$ (Neuber et al., 1988; Kurzawa and von Zahn, 1990). Climatological mean temperatures for the $50 \mathrm{~km}-$ $120 \mathrm{~km}$ altitude range have been derived from metal resonance lidar, falling sphere and in situ rocket measurements by Lübken and von Zahn (1991) for winter (October to March) and summer (June, July) at $69^{\circ} \mathrm{N}$. Some years later, Lübken (1999) published an updated summer (late April to September) climatology for the $35 \mathrm{~km}-93 \mathrm{~km}$ altitude range based on falling sphere measurements only from the years 19871997. Thulasirama and Nee (2002) analysed 7 years of temperature measurements from HRDI instrument on board the UARS satellite from the height range $75 \mathrm{~km}-105 \mathrm{~km}$ including measurements at $69^{\circ} \mathrm{N}$.

Only a few years of ALOMAR RMR lidar temperature data have been published so far. Hübner (1998) has analysed temperature measurements performed between January 1995 and April 1996. In 1999, Fiedler et al. published a total of 86 temperature profiles covering the year 1998. A stratospheric warming event in the winter $1997 / 98$ was investigated by von Zahn et al. (1998). However, a comprehensive analysis of the temperature data has not been available. This article will present the first coherent multi-year analysis of the middle atmospheric RMR lidar temperatures

Published by Copernicus Publications on behalf of the European Geosciences Union. 
covering the altitude range $30 \mathrm{~km}$ to $85 \mathrm{~km}$ during winter and $30 \mathrm{~km}$ to $65 \mathrm{~km}$ in summer. The temperature climatology derived from the RMR lidar measurements will be compared over the entire altitude range to other reference atmospheres like CIRA86, NRLMSISE00 and Lübken1999 (Fleming et al., 1990; Picone et al., 2002; Lübken, 1999). Up to the stratopause operational analyses from the European Centre for Medium-Range Weather Forecasts (ECMWF) are available for comparison. The lidar data are also combined with the falling sphere summer climatology and the ECMWF analyses below $30 \mathrm{~km}$ to yield a consistent temperature climatology for the $0 \mathrm{~km}-85 \mathrm{~km}$ altitude range at $69^{\circ} \mathrm{N}$.

Operating a lidar in the Arctic poses major challenges due to the harsh weather conditions and the need of a very stable lidar system which can be run by trained operators to collect as many observations as possible. Besides the ALOMAR RMR lidar, there are only five other lidar stations for mesospheric research at comparable northern latitudes: The Bonn University lidar at the Esrange in northern Sweden at $69^{\circ} \mathrm{N}$ (Blum and Fricke, 2005), the ARCLITE lidar in Søndrestrøm on Greenland at $67^{\circ} \mathrm{N}$ (Thayer et al., 1997), the Eureka lidar in the Canadian Arctic at $80^{\circ} \mathrm{N}$ (Whiteway and Carswell, 1994), the University of Rome lidar at Thule on Greenland $\left(76^{\circ} \mathrm{N}\right.$ ) (Di Girolamo et al., 1994) and the lidars at NyÅlesund on Spitzbergen $\left(79^{\circ} \mathrm{N}\right)$ (McGee et al., 1998). Although some wintertime temperatures have been published from these lidar stations (e.g. Duck et al., 2000; Blum, 2003; Blum and Fricke, 2008), none of these lidar systems has so far produced a temperature data set that spans the whole year including the summer. Reasons for this are the technical difficulties of measuring temperatures in the polar summer middle atmosphere by lidar, the large effort and manpower needed to operate an Arctic lidar system and the weather conditions. In contrast to the ALOMAR RMR lidar, the other systems also have been operated only during campaigns and not year-round.

This article starts with a description of the RMR lidar instrument in Sect. 2 which also details the available data set. Section 3 describes the Rayleigh lidar temperature analysis which has been applied to convert the lidar measurements to temperature profiles. The observed temperatures are presented in Sect. 4. Comparisons of our temperature observations to other temperature data sets are discussed in Sect. 6. Finally the conclusions of this study are presented in Sect. 7.

\section{Instrument and data set}

The ALOMAR RMR lidar was specifically developed for its location in the Norwegian Arctic at $\left(69.28^{\circ} \mathrm{N}, 16.01^{\circ} \mathrm{E}\right)$. At this high latitude, a major challenge for lidar observations is the four month period around summer solstice when it never gets dark. A lidar placed in this region therefore needs to be able to measure during full daylight conditions to allow measurements during the summer months. The ALOMAR
RMR lidar was tuned in all its technical realisation to measure throughout the whole year. This requires narrow bandpass optical filtering technology using single and double Fabry-Perot interferometers (etalons), a small field-of-view (FOV) of the telescopes and powerful lasers.

The RMR lidar consists of two Cassegrain type telescopes with $1.8 \mathrm{~m}$ diameter primary mirrors and $60 \mathrm{~cm}$ diameter $\mathrm{sec}-$ ondary mirrors each. The telescopes are mounted on motorised sockets which allow them to be tilted up to $30^{\circ}$ offzenith. Each telescope covers a $90^{\circ}$ azimuth range so that one of them can be tilted to all azimuths between west and north $\left(270^{\circ}-360^{\circ}\right)$ and the other between east and south $\left(90^{\circ}-\right.$ $\left.180^{\circ}\right)$. This configuration allows common-volume observations with both telescopes pointing vertically as well as simultaneous measurements at two different places in the atmosphere (Baumgarten et al., 2002).

Since a constant overlap of laser beam (beam divergence $<70 \mu \mathrm{rad}$ ) and telescope FOV (full angle of $180 \mu \mathrm{rad} \widehat{=} 18 \mathrm{~m}$ at $100 \mathrm{~km}$ altitude) at all times is needed for accurate determination of atmospheric temperatures with the RMR lidar, an automatic beam stabilisation system has been developed which uses a camera to observe the position of the laser beam in the FOV at $1 \mathrm{~km}$ distance and moves the last laser beam guiding mirror to keep the laser beam centred inside the FOV (Schöch and Baumgarten, 2003). This allows for very stable measurements even in marginal weather conditions when the telescope structure deforms due to heating by sunlight which can vary quickly due to tropospheric clouds.

The emitter system of the ALOMAR RMR lidar uses two seeded Nd:YAG power lasers which produce short laser pulses with pulse lengths of around $10 \mathrm{~ns}$. The fundamental wavelength of the Nd:YAG lasers is $1064 \mathrm{~nm}$. Two other wavelengths of $532 \mathrm{~nm}$ and $355 \mathrm{~nm}$ are produced through doubling and tripling of the frequency of the laser light by nonlinear processes in optical crystals. The seeder is a continuous-wave Nd:YAG diode laser with frequency doubling that is stabilised through iodine absorption spectroscopy (Fiedler and von Cossart, 1999). The seeding is applied to attain a small bandwidth for the pulses of the power lasers (near Gaussian pulse shape) and to keep the centre wavelength of the power lasers stable. Both characteristics are needed for the spectral filters applied to be able to measure during daylight conditions (Rees et al., 2000). On the laser table, a beam direction stabilisation is installed to keep the direction of the beam that leaves the laser table constant (Fiedler and von Cossart, 1999). Before leaving the laser table, the beam is widened from $1 \mathrm{~cm}$ diameter to $20 \mathrm{~cm}$ diameter to reduce the divergence of the laser beam to less than $70 \mu \mathrm{rad}$. Additionally, this avoids nonlinear effects during the propagation through the atmosphere as discussed e.g. by Martin and Winfield (1988).

A more detailed description of the design and implementation of the ALOMAR RMR lidar has been published by von Zahn et al. (2000). 
The lidar data analysed in this study have been recorded with a temporal resolution of $1 \mathrm{~min}-3 \mathrm{~min}$ and an altitude resolution of $130 \mathrm{~m}-150 \mathrm{~m}$ (depending on the tilting angle of the telescopes). Summation in time and smoothing in height has been applied during the analyses to improve the $\mathrm{S} / \mathrm{N}$ ratio (see Sect. 3).

The first measurements with the RMR lidar were performed on 19 June 1994, starting with only one laser and a $60 \mathrm{~cm}$ telescope (von Cossart et al., 1995). The large telescopes were installed in summer 1996 and the regular operation of one of the large telescopes started in 1997. Since May 1999 both systems can be operated simultaneously. While working through the data set, it became clear that a consistent quality of the derived temperature profiles was only found from 1997 onwards. This is due to frequent changes to the system prior to 1997 which do not allow a coherent software based derivation of the temperatures. In September 2005 the telescopes were refurbished with new primary mirrors which might affect the focusing and hence the overlap of the laser beam and the telescope FOV. This effect has not been fully investigated yet. Therefore the analysis in this work comprises the nine years from 1997 to August 2005. From this time period, 834 measurements which lasted for more than two hours were included in the temperature analysis presented in this study. The detailed measurement statistics for each year are listed in Table 1.

In this work, a measurement is defined as a period of RMR lidar operation with constant tilting angle of the telescope and gaps not longer than three hours. When both lasers and telescopes were operated, it was counted as two measurements since in most cases different regions of the atmosphere were sounded when one or both telescopes were tilted. The daily and seasonal coverage of all the RMR lidar measurements from 1997 to 2005 is shown in Fig. 1 in which night-time conditions are shaded. The measurements cover nearly all $24 \mathrm{~h}$ during the summer months and most of the day during winter. There are some gaps during the early morning hours in spring and autumn and at the end of December. Daytime measurements in spring and autumn have only been possible after a change in the detector setup in autumn 2001 which enabled a fast switch-over between daytime and nighttime configuration of the detection channels. Since the major commitment of the RMR lidar team also has been to noctilucent cloud measurements in summer and polar stratospheric cloud measurements in winter, the measurement efforts were concentrated on these seasons which is visible in the measurement distribution. Another reason for the gaps in spring and autumn is the weather which is dominated by overcast weather at ALOMAR during these times of the year. Nevertheless, since the detector upgrade in 2001, a number of measurements could be performed so that there are only few remaining periods with no measurements.

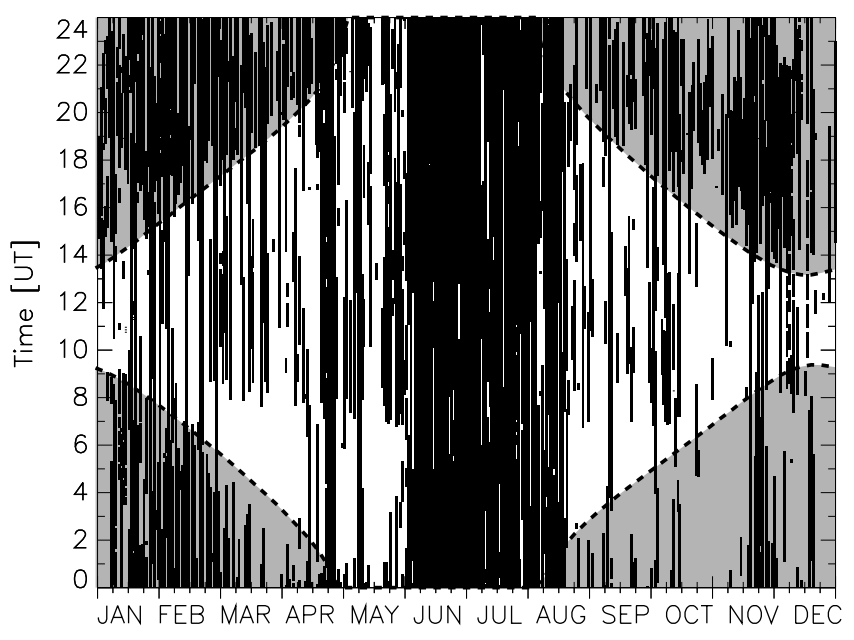

Fig. 1. Distribution of the combined data set from 1997-2005 as a function of time of day and season. The dashed line marks civil twilight (solar elevation angle $-5^{\circ}$ ). Night-time conditions are shaded. Measurements are indicated by black bars.

\section{Method}

The raw signal from a lidar can be used to deduce a height profile of the relative atmospheric density when different technical aspects and atmospheric effects have been properly accounted for. Section A2 in Appendix A describes in detail how this has been done for the data presented here. From the relative density profile the temperature profile can be calculated. Assuming hydrostatic equilibrium, the relative density profile is converted to a height profile of the atmospheric temperature through integration (e.g. Kent and Wright, 1970; Hauchecorne and Chanin, 1980):

$T(z)=\frac{n_{0}}{n(z)} \cdot T_{0}+\frac{M}{k_{B}} \int_{z_{0}}^{z} g\left(z^{\prime}\right) \cdot \frac{n\left(z^{\prime}\right)}{n(z)} \cdot d z^{\prime}$,

where $z$ is altitude, $T$ is the temperature, $n$ the atmospheric number density, $g$ the Earth's gravitational acceleration, $M$ the mean molecular weight of air and $k_{B}$ the Boltzmann constant. Also needed is the atmospheric temperature $T_{0}$ at the upper limit of the lidar signal. This start temperature is not known a-priori, so it has to be taken from a reference atmosphere like CIRA86 (Fleming et al., 1990) or NRLMSISE00 (Picone et al., 2002) or from another independent lidar system like a metal resonance lidar as detailed by Alpers et al. (2004). Since such a lidar only recently has become available at ALOMAR (She et al., 2002), all temperature profiles used in this work are calculated with start temperatures taken from NRLMSISE00. The integration is then performed downwards from the start altitude $z_{0}$. The advantage of the above algorithm is that the integral converges towards the true atmospheric temperature within one to two scale heights below the start height $z_{0}$ at the top of 
Table 1. Number of ALOMAR RMR lidar measurements per month which entered the temperature climatology. All measurements longer than two hours were included. The longest measurement lasted for $132 \mathrm{~h}$. In September 2005 the telescopes received a major upgrade changing their characteristics. Therefore we restricted the analysis to the data up to August 2005.

\begin{tabular}{cccccccccccccc}
\hline Year & Jan & Feb & Mar & Apr & May & Jun & Jul & Aug & Sep & Oct & Nov & Dec & Sum \\
\hline 1997 & 5 & 9 & 2 & 3 & 2 & 8 & 11 & 3 & 1 & 3 & 6 & 5 & 58 \\
1998 & 6 & 5 & 8 & 2 & 1 & 11 & 17 & 15 & 3 & 3 & 3 & 3 & 77 \\
1999 & 11 & 5 & 5 & 3 & 13 & 7 & 9 & 6 & 4 & 1 & 2 & 3 & 69 \\
2000 & 3 & 6 & 3 & 4 & 7 & 6 & 19 & 10 & 0 & 6 & 12 & 5 & 81 \\
2001 & 8 & 13 & 11 & 0 & 0 & 13 & 10 & 10 & 0 & 0 & 2 & 2 & 69 \\
2002 & 15 & 8 & 7 & 7 & 11 & 26 & 27 & 13 & 7 & 14 & 10 & 7 & 152 \\
2003 & 9 & 9 & 2 & 9 & 7 & 18 & 21 & 16 & 10 & 10 & 11 & 0 & 122 \\
2004 & 7 & 4 & 15 & 20 & 4 & 9 & 24 & 16 & 4 & 9 & 1 & 4 & 117 \\
2005 & 14 & 11 & 9 & 8 & 13 & 9 & 13 & 12 & - & - & - & - & 89 \\
& & & & & & & & & & & & & \\
Sum & 78 & 70 & 62 & 56 & 58 & 107 & 151 & 101 & 29 & 46 & 47 & 29 & 834 \\
\hline
\end{tabular}

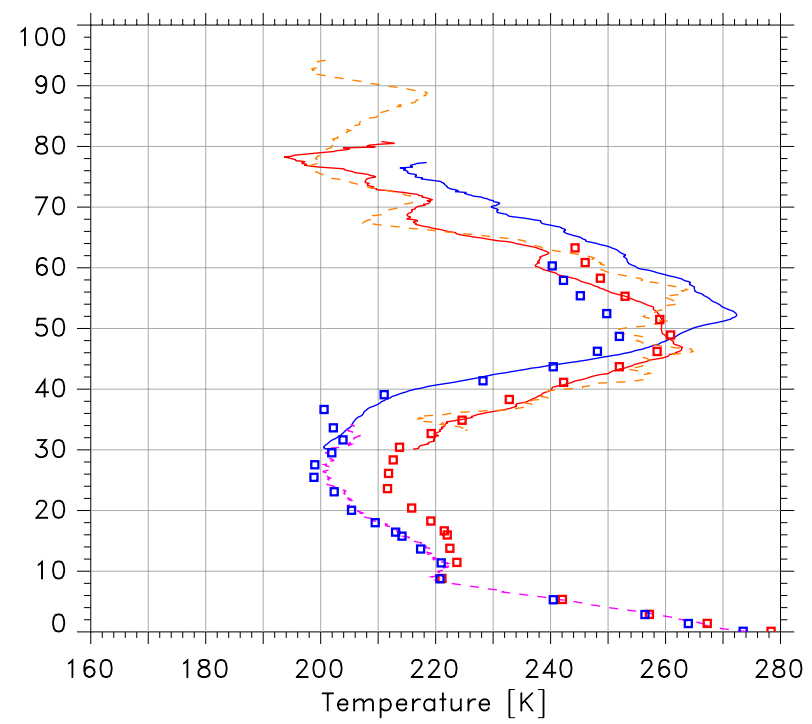

Fig. 2. RMR lidar temperatures calculated from Eq. (1) for 30 September 2002 (red) and 7 November 2002 (blue). Temperature profiles from simultaneous falling sphere (30 September 2002, orange) and radiosonde (7 November 2007, violet) measurements as well as from ECMWF operational analyses (squares) at $\left(70^{\circ} \mathrm{N}, 15^{\circ} \mathrm{E}\right)$ are included to show that the lidar temperature measurements agree with other independent methods.

the profile. Applying Gaussian error propagation, the statistical uncertainty at each altitude of the resulting temperature profile is estimated.

As Eq. (1) only involves density ratios, the lidar instrument does not have to be calibrated for absolute densities (as long as the proportionality factor is independent of height). This method is restricted to heights where there is no aerosol in the atmosphere. When aerosols are present, they contribute to the lidar signal which then is no longer directly proportional to the air density. Therefore the lower limit for our analysis is $30 \mathrm{~km}$ which is in general above the aerosol layer in the lower stratosphere (Junge et al., 1961).

All temperature profiles shown in this study are calculated from the RMR lidar signal at $532 \mathrm{~nm}$. The backscattered photons from all laser shots during the measurement having a minimum duration of two hours are integrated to increase the $\mathrm{S} / \mathrm{N}$ ratio. For the same reason, the count rate profiles are smoothed in height with a $2.25 \mathrm{~km}$ running-average filter (15 range bins). The increased $\mathrm{S} / \mathrm{N}$ ratio decreases the statistical uncertainty of the count rate profiles at all heights. Therefore the calculated temperature profiles which are restricted to a statistical uncertainty at the upper end of $5 \mathrm{~K}$ reach higher altitudes after integration and smoothing. The temporal integration also averages out structures with small horizontal scales. This assures that the assumption of hydrostatic equilibrium is valid and applicable also under tilted telescope conditions.

When all non-linearities of the detectors have been accounted for (see Appendix A for details), the integrated relative density profiles from the lidar can be used to calculate temperature profiles. The algorithm is neither sensitive to changes in the laser power nor to changes of the transmission of the receiving system, of the detector efficiency or of the atmospheric transmission in the troposphere as long as these changes occur on timescales much larger than the $1 \mathrm{~ms}$ it takes to record the backscattered light from one single laser pulse emission. This is usually fulfilled for the ALOMAR RMR lidar.

An example for this method and the comparison to other independent measurements is shown in Fig. 2 which shows two RMR lidar temperature profiles from 30 September 2002 21:42 UT-00:22 UT (red solid line) and 7 November 2002 14:20 UT-19:56 UT (blue solid line). The orange dashed line shows the temperature profile obtained from a falling sphere 


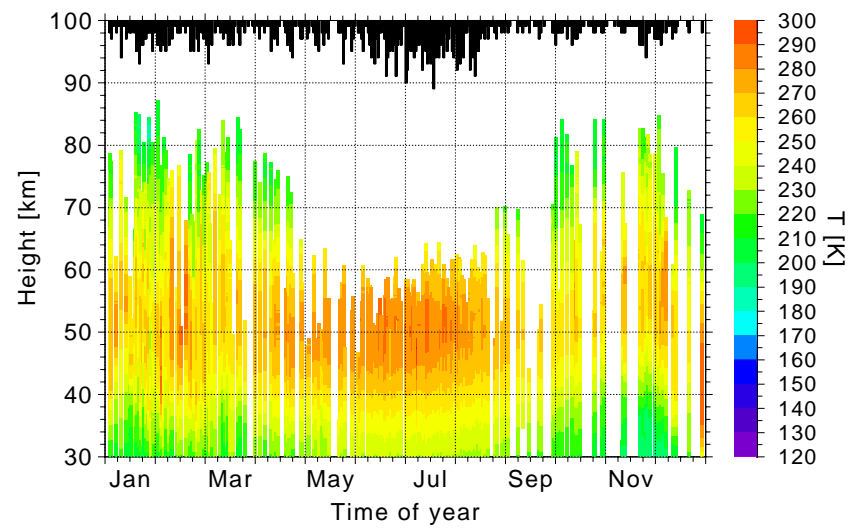

Fig. 3. Seasonal temperature variation during the years 1997-2005. Multiple measurements on the same day are averaged. The black bars give the number of measurements on each day $(1 \mathrm{~km} \widehat{=} 1$ measurement). The gaps in mid-May and at the end of December are caused by missing data due to unfavourable weather conditions.

meteorological rocket launched during the ROMA (Rocket borne Observations of the Middle Atmosphere) campaign in autumn 2002 on 30 September 2002 23:05 UT (Müllemann, 2004). The red and orange profiles agree well in the upper stratosphere. In the mesosphere there are some larger deviations that are due to the different temporal resolution of both instruments. While the falling sphere measurement takes only a few minutes, the lidar profile has been integrated over $2.5 \mathrm{~h}$. The violet dashed line shows the temperature profile from a radiosonde launched on 7 November 2002 16:08 UT. The small temperature difference between the blue and the violet profiles at $30 \mathrm{~km}$ is due to the horizontal distance of $250 \mathrm{~km}$ between the radiosonde and the vertical lidar beam at this altitude. Figure 2 also shows temperature profiles from operational ECMWF analyses on 1 October 2002 00:00 UT (red squares) and 7 November 2002 18:00 UT (blue squares). The temperature profiles obtained from the RMR lidar and the ECMWF analyses agree well for the measurement on 30 September 2002. On 7 November 2002, the lidar observed much warmer temperatures in the lower mesosphere than shown by ECMWF. This is probably due to a local warming event above ALOMAR that is not well resolved in the ECMWF data set. A more detailed comparison of RMR lidar and ECMWF temperature profiles is presented in Sect. 6.

\section{Temperature climatology}

To investigate the seasonal variation of the middle atmospheric temperatures above ALOMAR, the 834 temperature profiles in the years 1997 to 2005 were used to calculate daily means. As the altitude coverage of the single profiles on one day varied depending on the strength of the RMR lidar signal

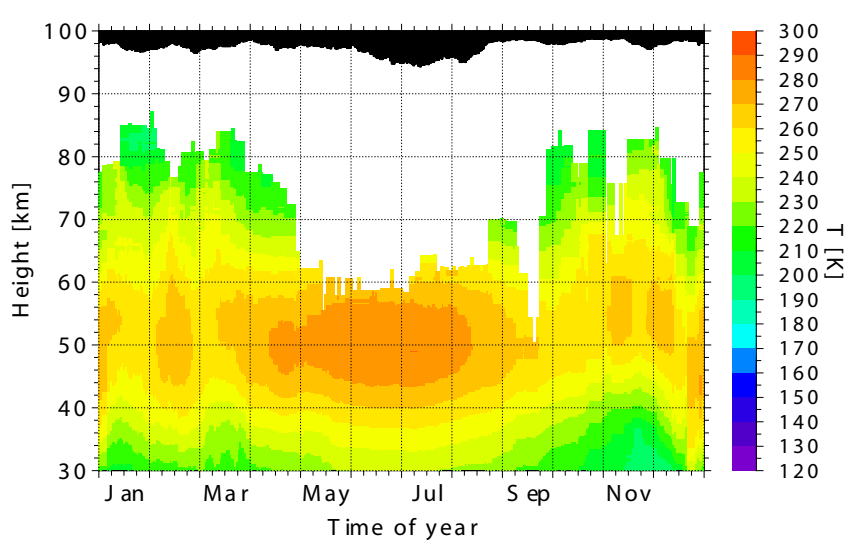

Fig. 4. RMR lidar temperatures from Fig. 3 but now smoothed with a 15-day running-average filter. This gives a better estimate of the mean seasonal temperatures and fills the smaller gaps. No additional smoothing in height has been applied. The black bars are smoothed with the same 15-day filter.

during the measurements, the number of measurements entering the daily means varies slightly at the upper end of the profiles. These daily mean temperatures are shown as a function of altitude and day of year in Fig. 3. The temperature is colour-coded and altitudes or times without measurements are shown in white. The number of measurements on each day is given by the black bars in the upper part of the diagram (1 km corresponding to one measurement). There are a few gaps e.g. in November and at the end of December which are caused by missing data due to adverse weather conditions. The upper altitude limit of the temperature profiles is lower in summer due to the higher solar background compared to the wintertime measurements.

Figure 3 shows the temperature maximum of the stratopause around $50 \mathrm{~km}$ with lower temperatures below and above. It is also evident that although the stratopause is generally warmer in summer than in winter, there are times when the winter stratopause is as warm as in summer or even warmer (e.g. in early January, mid-February or late December). These are times when the lidar observations are dominated by stratospheric warmings during which the stratopause temperature can exceed $320 \mathrm{~K}$ (von Zahn et al., 1998).

To get a better estimate of the mean seasonal temperature variation, the daily profiles in Fig. 3 were smoothed in time by a 15-day running-average filter. No additional smoothing in height was applied. Figure 4 shows that this procedure smoothes over the gaps and gives a continuous temperature climatology from roughly $30 \mathrm{~km}$ to $85 \mathrm{~km}$ in winter and $30 \mathrm{~km}$ to $65 \mathrm{~km}$ during summer months. The middle stratosphere is approximately $20 \mathrm{~K}$ warmer in summer than in winter. At the stratopause, the difference between summer and winter is around $15 \mathrm{~K}$. There was a sudden stratospheric warming in nearly every winter in the years 


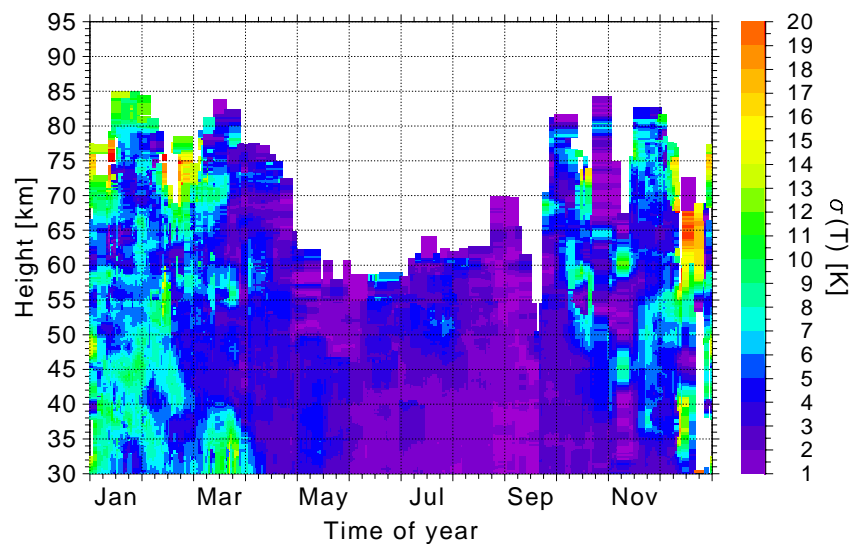

Fig. 5. Standard deviations of the single night-mean temperature profiles calculated for 15-day intervals. This gives an impression of the geophysical variability of the atmosphere above ALOMAR.

1997-2005 (Schöch, 2007). This is also apparent in the mean winter stratopause temperatures in Fig. 4. While the overall mean temperature of the upper stratosphere in winter (October-March) is around $260 \mathrm{~K}$ over ALOMAR, even the mean seasonal temperature is larger than $260 \mathrm{~K}$ for a number of periods (e.g. late December, early January, mid-February).

The geophysical variability of the temperature in the polar middle atmosphere has been estimated from the standard deviation of the observed temperature profiles and is shown in Fig. 5. To get a sufficient number of profiles, the standard deviations have been calculated over 15-day intervals. In summer, the standard deviations are below $5 \mathrm{~K}$ while they reach up to $25 \mathrm{~K}$ during the winter months. This is consistent with the observations from falling spheres at Andøya published by Lübken (1999) and is a result of the stronger wave activity in winter (both planetary and gravity waves) compared to summer (e.g. Theon et al., 1967; Lübken and von Zahn, 1991). A major reason for this difference is the westward summer circulation in the upper polar stratosphere/lower mesosphere which prevents the upward propagation of planetary waves. The winter circulation is eastward and thus does not prevent planetary waves from propagating upwards (Andrews et al., 1987). In contrast, gravity waves in the middle atmosphere have both eastward and westward horizontal phase speeds. Therefore some gravity waves can always propagate upward. However, due to the location of ALOMAR on the coast in Northern Norway, it is expected that a major part of the gravity waves above ALOMAR are mountain waves excited at the local topography around ALOMAR. Another source for gravity waves with long horizontal wavelengths is Greenland. Some waves are also expected upstream of the Scandinavian mountain ridge. Since tropospheric winds are usually stronger in winter than in summer, larger gravity wave amplitudes and occurrence rates are expected in winter and contribute to the

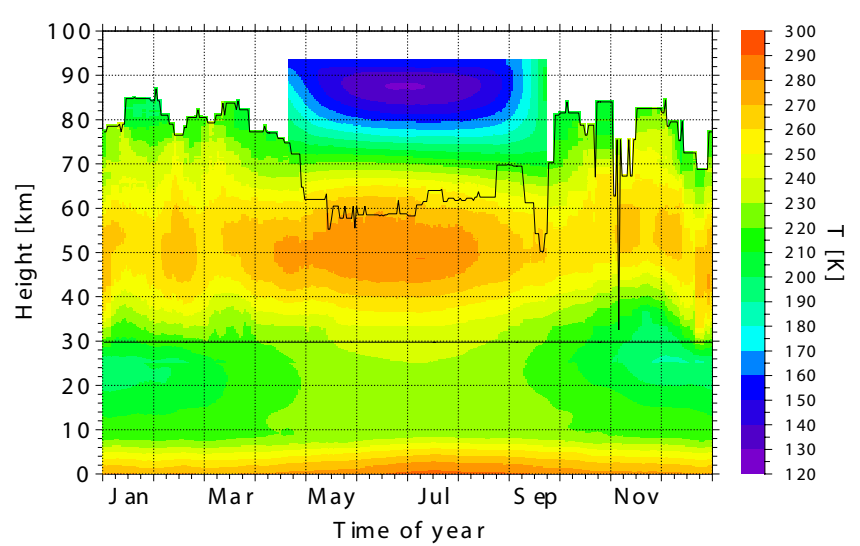

Fig. 6. Combination of the (smoothed) RMR lidar temperatures from Fig. 4 with the Lübken1999 climatology in the summer upper mesosphere and the mean ECMWF temperatures interpolated to $\left(70^{\circ} \mathrm{N}, 15^{\circ} \mathrm{E}\right)$ for 1997 to 2005 below $30 \mathrm{~km}$. The latter were smoothed with a 15-day running-average filter. The upper and lower limits of the RMR lidar data are marked by black lines. See text for details of the interpolation at the borders.

larger observed temperature variability compared to the summer months.

\section{Combined temperature climatology}

To extend the altitude coverage of the lidar temperature climatology, three data sets were combined: the RMR lidar temperatures shown in the previous section, the Lübken1999 reference atmosphere (Lübken, 1999) in the summer upper mesosphere and the mean ECMWF temperatures at $0 \mathrm{UT}$ for 1997 to 2005 below $30 \mathrm{~km}$. The combined temperature climatology is shown in Fig. 6. The ECMWF temperatures were interpolated to the geographical location $\left(70^{\circ} \mathrm{N}, 15^{\circ} \mathrm{E}\right)$ and smoothed with a 15-day running-average filter to have a similar temporal resolution as the lidar data. The black lines marks the upper and lower limits of the RMR lidar data where it overlaps with the Lübken1999 and ECMWF temperatures. The transition from one data set to another was smoothed by a linear interpolation over $8 \mathrm{~km}$ around the black line. The remaining discontinuities are very small $(<2 \mathrm{~K})$. This combined temperature climatology covering the entire lower and middle atmosphere during the whole year is listed in Appendix B in Table B1.

Of the three data sets shown in Fig. 6, the RMR lidar shows the highest temperature variability. The falling sphere data shows much less variability. This is due to the averaging and spline-fitting applied to the original data in order to compose the Lübken1999 reference atmosphere (Lübken, 1999). In the case of the ECMWF data set, the spatial resolution of the model is probably to low to include all geophysical 

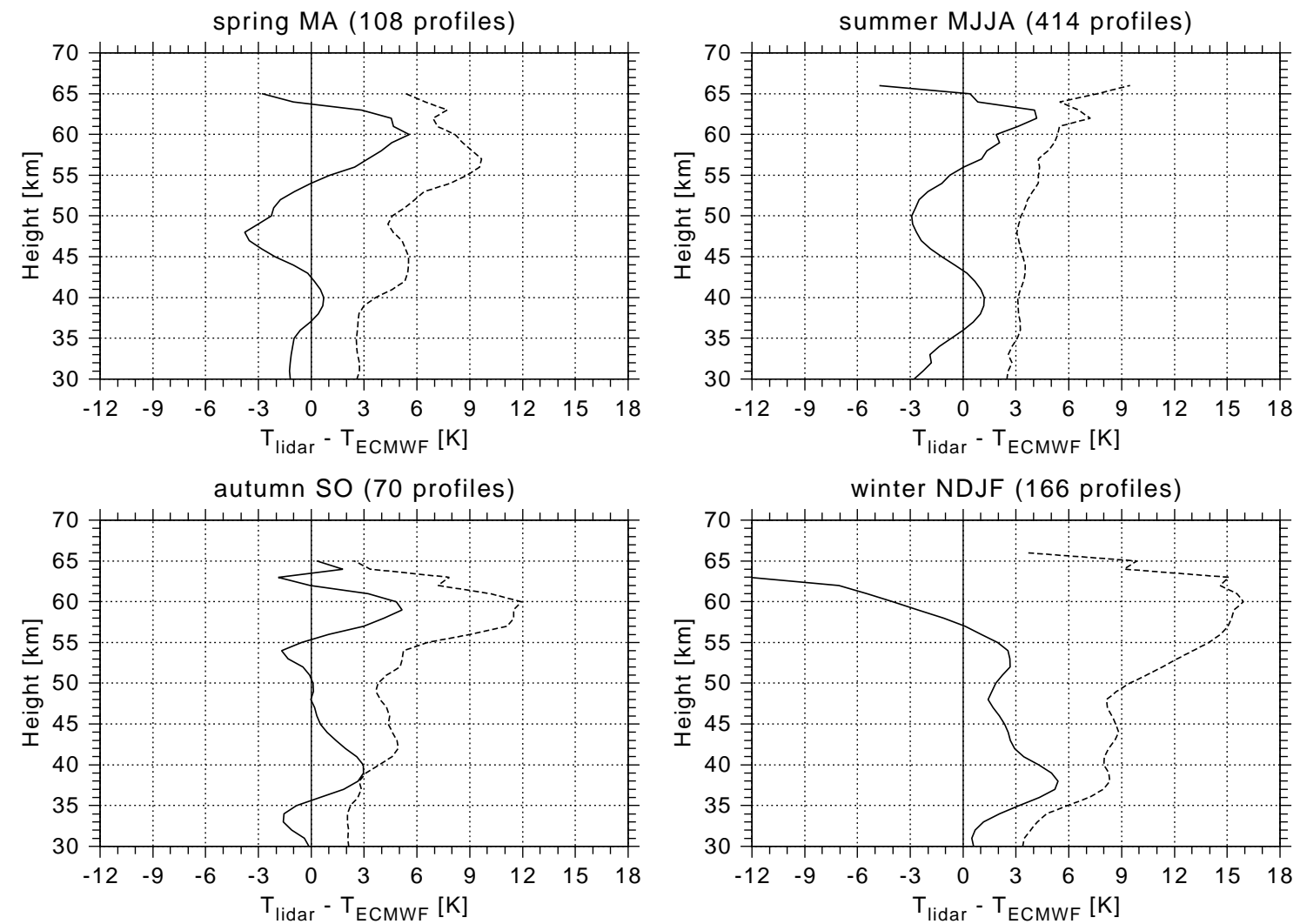

Fig. 7. Statistical analysis of the deviations between RMR lidar observed temperatures and ECMWF operational analyses divided by seasons. Positive mean deviations (solid line) signify heights at which the ECMWF model calculates temperatures that are lower than those observed with the RMR lidar. The dashed lines give the $1-\sigma$ range of the deviations.

variability observed by the RMR lidar. Further differences between the three data sets will be discussed in the next section.

\section{Comparison to other data sets}

The comprehensive temperature data set described in Sect. 4 is now compared to other temperature date sets. At polar latitudes, no other lidar temperature climatology is available which comprises a comparable number of measurements and has a similar coverage of the whole year. Therefore it was not possible to compare the ALOMAR RMR lidar seasonal temperature variation to other lidar derived data sets. The large variability in winter even at one site and the geographical spread of the lidar stations prevent a useful comparison of the winter data sets. Instead, comparisons with the reference atmospheres CIRA86, NRLMSISE00 and Lübken1999 and with ECMWF analyses of the operational model version ("operational ECMWF") will be shown. This gives the possibility to assess how good a reference atmosphere which usually only gives zonal mean values describes the temperatures above a specific site, in our case the ALOMAR observatory.
For the operational ECMWF analyses, it is interesting to see to which degree they represent the small scales of the observed temperature structure at our site and the timing of temperature extremes like stratospheric warmings.

A statistical comparison of RMR lidar measurements and operational ECMWF analyses is shown in Fig. 7. The operational ECMWF analyses were available every six hours at 00:00 UT, 06:00 UT, 12:00 UT and 18:00 UT for the location $\left(70^{\circ} \mathrm{N}, 15^{\circ} \mathrm{E}\right)$. For each RMR lidar measurement, the ECMWF profile closest in time to the centre-time of the lidar measurement was selected. Then the measurements were grouped into seasons for spring (March, April), summer (May-August), autumn (September, October) and winter (November-February). The differences were calculated by subtracting the ECMWF temperatures from the RMR lidar temperatures. Figure 7 shows the mean deviation for each season (solid lines) and the standard deviations (1- $\sigma$ spread, dashed lines) of the set of differences from the mean for each season. The error of the mean is typically $<0.6 \mathrm{~K}$ at the upper end and decreases rapidly below. By selecting the ECMWF profile closest in time the calculated temperature differences between RMR lidar measurements and ECMWF analyses are not influenced by tidal temperature changes. 


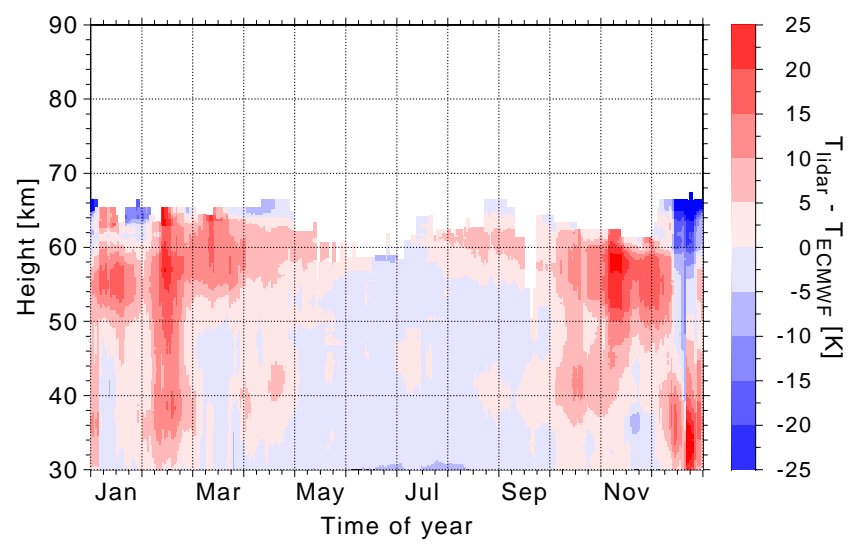

Fig. 8. Comparison of the RMR lidar seasonal temperature variation to the mean ECMWF temperature at $\left(70^{\circ} \mathrm{N}, 15^{\circ} \mathrm{E}\right)$ during the years 1997-2005. The ECMWF temperatures were smoothed with a 15-day running-average filter for this comparison.

For all seasons except winter, the mean deviations show a general increase with height and change sign several times. But the mean deviations remain more or less centred around the zero line. The spread of the profiles grows with height throughout the stratosphere. In the lower mesosphere the spread decreases again with height except for the summer season. The standard deviation is about $3 \mathrm{~K}$ up to $40 \mathrm{~km}$, while it is $3 \mathrm{~K}-10 \mathrm{~K}$ above. The latter implies that the ECMWF gives a good approximation of the lidar observed temperature structure with a precision of about $3 \mathrm{~K}$ and no systematic deviations. Since ECMWF is mostly assimilating data from radiosondes and satellites in the lower atmosphere and only fewer data from higher altitudes, it is expected that the spread of the differences grows with height. Also the vertical distance between the pressure level of the ECMWF model grows with height and border effects are expected at the upper end of the ECMWF profiles. This makes it more difficult for the model to resolve the correct stratopause height and temperature, especially when the stratopause temperature maximum is confined to a small altitude region.

In winter there seems to be a systematic shift of the ECMWF temperatures towards too low values below $55 \mathrm{~km}$ with a maximum of the mean deviation between $35 \mathrm{~km}$ and $40 \mathrm{~km}$. Above $60 \mathrm{~km}$ and hence at the upper border of the ECMWF model, the ECMWF temperatures are on average too high. This implies that the stratopause altitude is on average too high in the ECMWF temperature profiles during winter. Also the spread of the differences from the mean at each altitude is up to three times larger than in the other seasons. Part of these differences are probably due to movements of the polar vortex and stronger planetary wave activity in winter which are not completely resolved by the ECMWF analyses. The exact timing and magnitude of stratospheric warmings above our site are also found to contribute to the larger differences between RMR lidar observations and ECMWF analyses in winter compared to the other seasons.

Another way to explore the differences between RMR lidar and ECMWF operational analyses is the comparison of the average temperatures from the years 1997 to 2005. Figure 8 displays the difference between the mean ECMWF temperature field above $30 \mathrm{~km}$ and the mean RMR lidar seasonal temperature variations from Fig. 4. For a comparable temporal resolution, the ECMWF analyses have been smoothed by a 15-day running-average filter. Again, the agreement is good in summer with differences generally below $5 \mathrm{~K}$. In the lower mesosphere during winter, the differences are much larger than in summer and for most height regions the temperatures from ECMWF are lower than those observed with the RMR lidar. In the upper winter stratosphere, the differences are largest during times of sudden stratospheric warming events when they reach up to $25 \mathrm{~K}$. Only in December in the lower mesosphere, the mean ECMWF temperatures are much higher than the RMR lidar temperatures. This is due to the strong sudden stratospheric warming events at the end of December 2000 and 2002 which dominate the mean RMR lidar temperature during this time of the year. This shows that the ECMWF analyses do not resolve the mesospheric cooling associated with sudden stratospheric warming events correctly.

Turning to the comparison of the RMR lidar temperatures to reference atmospheres, Fig. 9 presents the difference between the RMR lidar seasonal mean temperature field and the NRLMSISE00, CIRA86 and Lübken1999 reference atmospheres (Picone et al., 2002; Fleming et al., 1990; Lübken, 1999). The NRLMSISE00 data set was calculated for the latitude $69^{\circ} \mathrm{N}$. The solar parameters that can be specified for NRLMSISE00 were held constant at mean values $\left(\mathrm{F}_{10.7}=150, \mathrm{AP}=4\right)$. This represents mean solar conditions and is advised in the NRLMSISE00 code for altitudes below $80 \mathrm{~km}$. We have investigated the sensitivity to these parameters and observed that the effect on the temperatures is small. It is less than $0.1 \mathrm{~K}$ for altitudes below $80 \mathrm{~km}$, and less than $1 \mathrm{~K}$ for altitudes up to $90 \mathrm{~km}$. In summer, the NRLMSISE00 reference atmosphere is colder than the RMR lidar temperatures in the upper stratosphere and warmer in the lower mesosphere (upper panel of Fig. 9). The differences reach up to $15 \mathrm{~K}$ which is three times the maximum differences seen in summer between RMR lidar and ECMWF analyses. In winter, the differences are even larger but follow the same pattern with an additional cold bias of the NRLMSISE00 reference atmosphere in the upper mesosphere above $75 \mathrm{~km}$. Similarly large differences between temperature measurements and NRLMSISE00 at high latitudes have been found by Pan and Gardner (2003) for measurements above South Pole. The strong positive bias in the difference between NRLMSISE00 and the RMR lidar in February and at the end of December is again due to sudden stratospheric warming events that dominate the RMR lidar mean during these times of the year (see Fig. 3). 
The middle panel of Fig. 9 shows the differences between the mean RMR lidar temperatures and the CIRA86 reference atmosphere. This is a previous standard atmosphere which is known to be inaccurate in the polar regions. The differences follow the same patterns as for the NRLMSISE00 reference atmosphere as expected because the data used to assemble the CIRA86 reference atmosphere were also later used to construct the MSISE90 reference atmosphere, a predecessor of NRLMSISE00. The differences between lidar observations and CIRA86 are somewhat larger than for NRLMSISE00, especially in the winter mesosphere. The comparison to CIRA86 is shown here because it is still widely used in the scientific community.

The Lübken1999 reference atmosphere (see lower panel of Fig. 9) only covers the period from end of April to late September. It was calculated from 89 falling sphere flights during the years 1987-1997. The RMR lidar temperatures are higher than Lübken1999 in the upper mesosphere at the end of April and in September while they are lower than Lübken1999 during the entire time in the stratosphere and lower mesosphere. The difference reaches up to $-10 \mathrm{~K}$ around $60 \mathrm{~km}$. In June and July, part of this difference may be due to the proximity to the upper border of the RMR lidar altitude range where there may still be a small influence of the start temperature $(\sim 5 \mathrm{~K})$ taken from NRLMSISE00 which is $\sim 10 \mathrm{~K}$ colder than Lübken 1999 in the lower mesosphere. Remember that the RMR lidar profiles have a statistical uncertainty of $5 \mathrm{~K}$ at the upper border (including the uncertainty of the start temperature) which could explain half of the observed differences. Another reason for the differences of the measurements performed by lidar and falling spheres at the same location may be the different years that were used to calculate the Lübken1999 (1987-1997) and the RMR lidar (1997-2005) mean temperatures.

A similar conclusion was reached by Blum and Fricke (2008) who compared lidar temperature measurements at Kiruna in northern Sweden $\left(68^{\circ} \mathrm{N}\right)$ with the Lübken 1999 reference atmosphere. Since their measurements were mostly taken around midnight which also is the time of most of the falling sphere launches, this confirms that tides do not have a strong influence on the observed temperature differences.

\section{Conclusions}

The middle atmosphere temperature data set obtained with the ALOMAR RMR lidar and combined with ECMWF and falling sphere data is unique because it covers the entire troposphere, stratosphere and mesosphere over nine years from 1997 to 2005. Additionally it is not restricted to night-time measurements, i.e. it includes the entire polar summer. For this high latitude, a lidar climatology spanning the whole year including the polar summer has not been available before. The large number of temperature profiles and good coverage of all seasons also is an advantage over other tem-

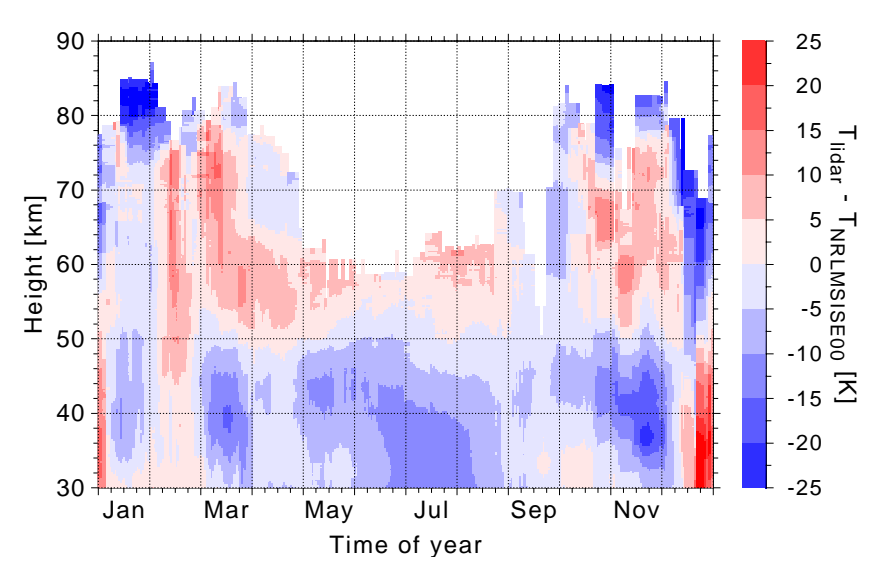

(a) Difference between RMR lidar mean temperatures and NRLMSISE00

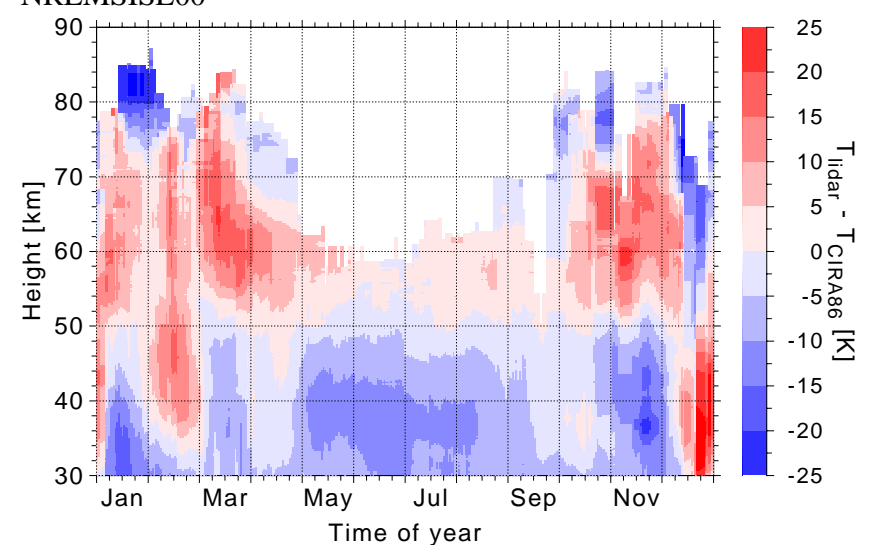

(b) Difference between RMR lidar mean temperatures and CIRA86

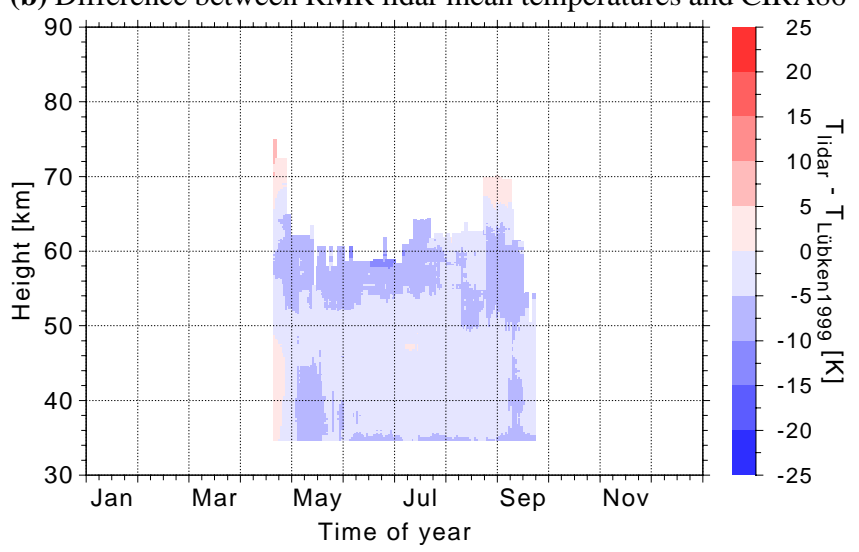

(c) Difference between RMR lidar mean temperatures and Lübken 1999

Fig. 9. Upper panel: Comparison of RMR lidar temperatures to the NRLMSISE00 reference atmosphere at $69^{\circ} \mathrm{N}$. Middle panel: Comparison of RMR lidar temperatures to the CIRA86 reference atmosphere at $70^{\circ} \mathrm{N}$. Lower panel: Comparison to the Lübken1999 reference atmosphere.

perature climatologies from campaign based lidar or falling sphere measurements (von Zahn and Neuber, 1987; von Zahn and Meyer, 1989; Lübken, 1999). The high temporal and 
vertical resolution of the RMR lidar is also better suited for the investigation of the short-periodic temperature variations and to resolve the detailed vertical structure of the temperature variations.

The temperature climatology from the RMR lidar observations covers the altitude range $30 \mathrm{~km}-85 \mathrm{~km}$ in winter and $30 \mathrm{~km}-65 \mathrm{~km}$ in summer. Comparing the RMR lidar temperature measurements with other data sets it is found that in summer the RMR lidar temperatures are up to $5 \mathrm{~K}$ colder than the Lübken1999 reference atmosphere in the stratosphere and up to $10 \mathrm{~K}$ colder in the mesosphere. Part of this difference is probably due to the different years used in the compilation by Lübken (1999). The differences to the reference atmospheres NRLMSISE00 and CIRA86 are significantly larger and reach up to $25 \mathrm{~K}$, especially in winter (see Fig. 9). The detailed comparison of simultaneous RMR lidar and ECMWF temperature profiles in Sect. 6 shows the best agreement in summer and the largest mean difference and variability of the differences in winter. The standard deviations of the differences between RMR lidar and ECMWF are about $3 \mathrm{~K}$ up to $40 \mathrm{~km}$ and increase above.

There are however significant deviations between the RMR lidar temperatures and the other data sets in certain altitude ranges and times of the year. Since the geophysical variability is smaller in summer than in winter, the differences between the data sets also is smaller in summer than in winter. The largest deviations were found at times of sudden stratospheric warming events which are not included in the reference atmospheres. The ECMWF analyses include the sudden stratospheric warming events but the timing and the magnitude of the sudden stratospheric warmings exactly above our ALOMAR site are not well resolved by the ECMWF analyses. The RMR lidar temperature climatology therefore is a good candidate to validate middle atmosphere models like the new Leibniz-Institute Middle Atmosphere (LIMA) model (Berger, 2008). These comparisons also stress the need for continuous lidar measurements to determine the middle atmosphere temperatures which at times deviate considerably from the reference atmospheres and the ECMWF analyses.

\section{Appendix A}

\section{Data processing}

This appendix describes the steps in the RMR lidar data processing necessary to derive temperature profiles from the measured lidar count rate profiles. More detailed descriptions of all these steps are available in Schöch (2007).

\section{A1 Record selection algorithm}

The ALOMAR RMR lidar is operated whenever permitted by the weather conditions. This includes times when tropo- spheric clouds or fog intermittently attenuate or even completely block the lidar signal. While the lidar electronics still record these profiles, they have to be excluded from the temperature calculations. The general strategy in selecting the periods for the summation is to maximise the $\mathrm{S} / \mathrm{N}$ ratio. The applied selection algorithms are described in the following paragraphs.

The electronic counters connected to the detectors of the RMR lidar sum the received signal over 2000-5000 laser pulses (67 s-167 s) before a raw count rate altitude profile is stored on disk. Such a single profile will be called "record" in the following discussion.

The first step is to remove records which obviously have disturbances caused by electronic interference. Although great care has been taken to shield all components of the detection system, occasionally a record shows spikes in single altitude bins or signal bursts over a broader height range which are caused by electronic disturbances. These records are excluded from the summation. Also records which are empty because a low cloud had blocked the laser light are excluded.

In the remaining records, the solar background in the $532 \mathrm{~nm}$ channels may still vary by as much as five orders of magnitude due to solar elevation changes while the signal may be strongly attenuated when the atmospheric transmission in the troposphere is low. We select those records which, when summed together, result in the largest $\mathrm{S} / \mathrm{N}$ ratio as follows. First the height where the Rayleigh lidar signal disappears into the background noise is determined for each record. This so-called "top altitude" is useful for the record selection since it is large for profiles with strong signal and low background and low when either the background is large or the signal weak. Then all records are selected that have top altitudes within $20 \%$ of the maximum top altitude. If the minimum top altitude is larger than $95 \%$ of the top altitude, all records are selected. The latter case marks a measurement under stable conditions where no special selection is necessary.

The result of this record selection is shown in Fig. A1 for the RMR lidar measurement on 5 February 2002 17:54 UT04:42 UT. The normalised count rate at $30 \mathrm{~km}$ altitude of each record is shown as red diamonds while the top altitude of the records is given by the blue dots. Empty symbols mark records which have not met the above criteria and are excluded from the summation. Obviously, records with either small signal or low top altitude are left out. The objective determination of this selection is achieved through the procedure described above.

\section{A2 Data processing steps}

Once the record selection has been done as described in the previous section, all remaining records inside the integration period are summed. This section describes the processing 
steps applied to this summed lidar raw data profile to convert it into a temperature profile.

An example of summed RMR lidar count rate profiles at the visible wavelength $532 \mathrm{~nm}$ is given in the left panel of Fig. A2 for the measurement on 13/14 February 2005 17:00 UT-5:00 UT. The integration time corresponds to 1292000 laser pulses. The three channels are intensitycascaded by means of partially reflecting optical beamsplitters dividing the incoming photons onto three detectors. This is necessary because the dynamic range of the lidar signal is too large for a single detector. The channels are marked as "high" (red), "middle" (violet) and "low" (blue) according to the covered altitude range which is determined by the reflectivity of the beam-splitters and the electronic gating of the detectors. For the "middle" channel, electronic noise in the detection system contributes to the count rate profile below $20 \mathrm{~km}$. The constant background at the upper end of the profiles is caused by the atmospheric background due to scattered solar photons, moonlight and air glow as well as electronic noise of the detection system.

To obtain a relative density profile from the lidar count rate profiles, several effects must be taken into account. The magnitudes of the different effects are shown in the right panel of Fig. A2 as percent adjustment to the lidar count rate profiles. From Eq. (1) it can be seen that this corresponds to a similar change of the derived temperature. Since temperatures during this measurement were between $200 \mathrm{~K}$ and $275 \mathrm{~K}$ (see right panel of Fig. A3), an adjustment as shown in Fig. A2b of e.g. $2 \%$ to the lidar count rate profiles corresponds to a change of the derived temperature of $4 \mathrm{~K}-5.5 \mathrm{~K}$. In the analyses included are:

- Detector dead-time:

The RMR lidar uses photomultipliers and avalanche photo diodes to detect the photons received by the telescopes. Both work in the photon counting mode. These detectors have a limit for the shortest interval between two successive photons that can be detected separately. As photon counting is a statistical Poisson process, this happens occasionally even if the signal is much lower than the maximum count rate of the detectors. More details about the dead-time compensation can be found in Hübner (1998) and Keckhut et al. (1993). For the photomultipliers used in the $532 \mathrm{~nm}$ channels, a dead-time of $7 \mathrm{~ns}$ is used. As the effect depends on the count rate, it is strongly height dependent and most important at the lower boundary of the channels where their signal is largest (see red, violet and blue lines in right panel of Fig. A2).

- Tilted telescopes:

One of the advantages of the ALOMAR RMR lidar over many other lidar systems is its ability to tilt the telescopes by up to $30^{\circ}$ from zenith. This changes the altitude resolution and hence the $d z^{\prime}$ in Eq. (1) from the

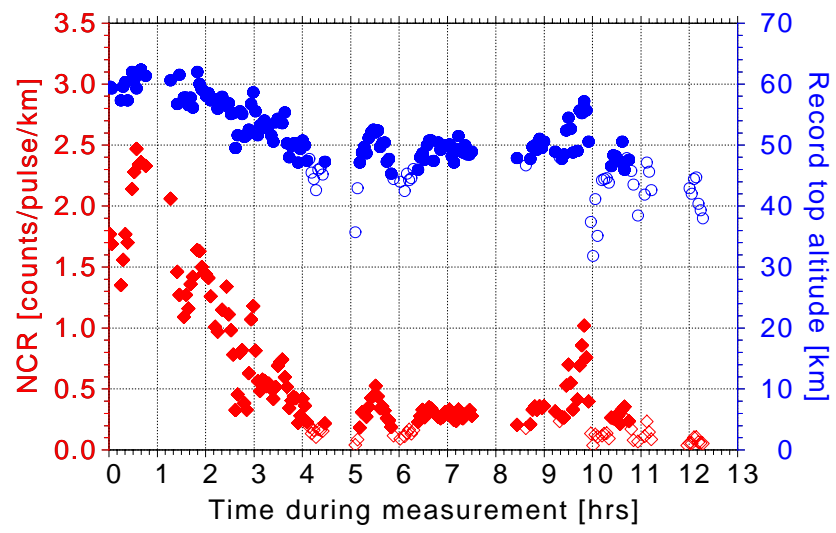

Fig. A1. Example of the record selection based on the normalised count rates (NCR) at $30 \mathrm{~km}$ (red, left scale) and top altitude (blue, right scale) for the measurement from 05.02.2002 17:54 UT04:42 UT. Empty symbols mark records which are excluded from the signal summation (see text for details).

usual $150 \mathrm{~m}$ for vertical measurements to $129.9 \mathrm{~m}$ for $30^{\circ}$ tilt angle.

- Rayleigh and ozone extinction:

Both the emitted laser light and the backscattered light experience extinction by air and ozone molecules whose magnitude depends on the wavelength of the light. Rayleigh scattering by air molecules is compensated using a pressure and density profile from the CIRA86 reference atmosphere and the known Rayleigh scattering cross-sections (see Bakan et al., 1988, Sect. 7.4). Above $40 \mathrm{~km}$ Rayleigh extinction becomes negligible (see orange line in right panel of Fig. A2). To compensate for ozone extinction, an ozone climatology by Fortuin and Langematz (1995) is used. The ozone scattering cross-section is taken from Burrows et al. (1999). Above $50 \mathrm{~km}$ there is very little ozone so that its extinction of the lidar signal can be neglected (see green line in right panel of Fig. A2). Between $30 \mathrm{~km}$ and $40 \mathrm{~km}$ the combined effect of Rayleigh and ozone extinction is smaller than $1.5 \mathrm{~K}$.

- Determination of upper end of Rayleigh signal:

The left panel of Fig. A2 shows that the exponentially decreasing Rayleigh signal disappears into the background around $105 \mathrm{~km}, 95 \mathrm{~km}$ and $85 \mathrm{~km}$ for the "high", "middle" and "low" channel, respectively. Since only the Rayleigh signal is of interest for the further analysis, this top altitude has to be determined for each channel. In this work, the quality of a polynomial fit to the median-filtered background is used for this purpose. The lower altitude limit is lowered in steps of $5 \mathrm{~km}$ until the difference between fitted background and raw signal in this altitude range is getting larger 


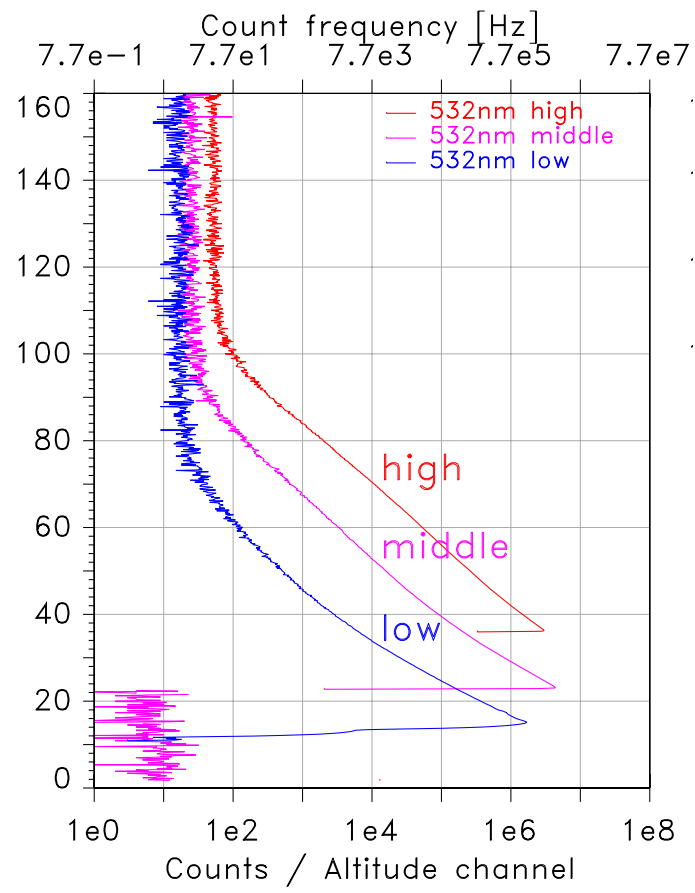

(a) Lidar count rate profiles

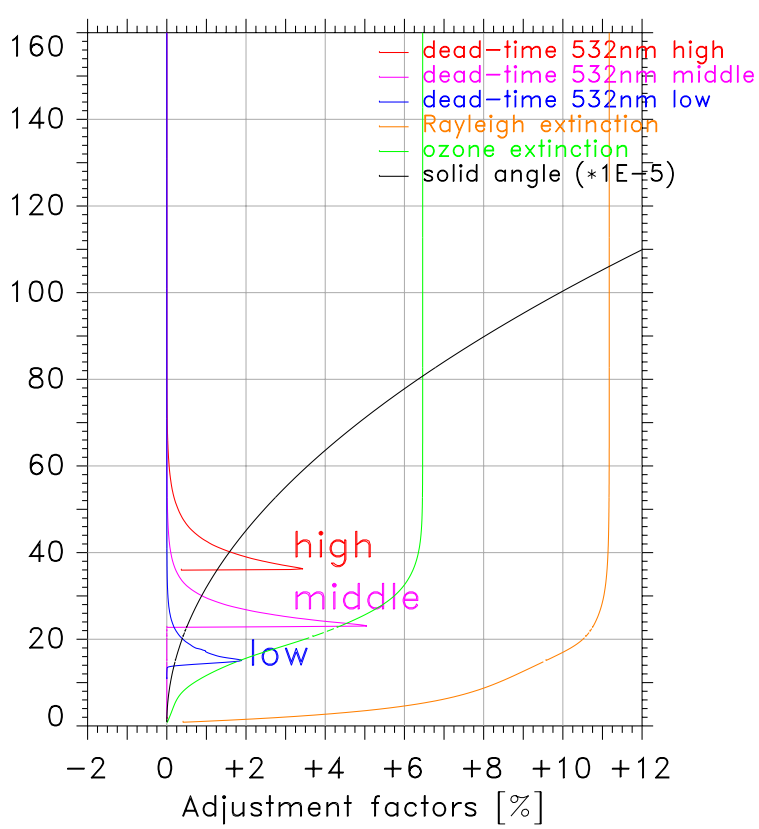

(b) Adjustment factors for different effects vs. height

Fig. A2. Left panel: Raw data profiles from the three intensity-cascaded channels at $532 \mathrm{~nm}$ after summation for the RMR lidar measurement on 13 February 200517 UT-5 UT (1 292000 laser pulses). The lower end of the profiles is given by the electronic gating of the detectors. The upper scale gives the equivalent count rate for the detectors. Note the exponential scale on the x-axis. Right panel: Adjustment factors for detector dead-time, extinction by air and ozone and the viewing geometry of the lidar (see text for details).

than twice the mean statistical uncertainty in the altitude range $150 \mathrm{~km}-250 \mathrm{~km}$. The upper altitude limit of the Rayleigh signal for the further analyses is then taken to be $10 \mathrm{~km}$ below this limit.

- Background subtraction:

The background due to scattered solar photons, air glow, stars and electronic noise of the detection system can be determined at the uppermost heights of the count rate profiles above the maximum altitude of the Rayleigh signal determined in the previous step. The background is determined in the altitude range from $25 \mathrm{~km}$ above the Rayleigh signal to $250 \mathrm{~km}$. For ideal detectors, the background should be constant over the entire altitude range. However, under certain circumstances the detectors of the RMR lidar produce a background which is decreasing with altitude. In this case the background has to be approximated by a linear or parabolic fit in the background altitude range. This fit is then used to extrapolate the background over the entire altitude range. To avoid erroneous fits due to statistical outliers, the background is smoothed with a median filter over 25 altitude bins before the fit is applied. Once the background is determined, it is subtracted from the lidar signal.
- Solid angle:

This is a purely geometric effect. The solid angle covered by the receiving telescope at the height of the scattering process decreases like the square of the distance between the scatterer and the telescope. Therefore the signal has to be multiplied by the square of the distance between telescope and scatterer to compensate for this geometric effect (see black line in the right panel of Fig. A2).

- Concatenation of lidar profiles:

After all the above effects have been compensated for, the lidar profiles from the three $532 \mathrm{~nm}$ channels are attached to each other to form a continuous profile throughout the middle atmosphere. This is done by calculating a mean scaling factor over $2 \mathrm{~km}$ altitude in the overlap region of two channels. The result is a relative atmospheric density profile as shown in the left panel of Fig. A3. It is smoothed with a running-average filter over 15 altitude bins $(\widehat{=} 2.25 \mathrm{~km}$ when the telescope points to zenith) to improve the $\mathrm{S} / \mathrm{N}$ ratio.

- Temperature integration:

The smoothed relative density profile is now integrated as described in Sect. 3 to yield a temperature profile in the aerosol-free part of the atmosphere above $30 \mathrm{~km}$ 


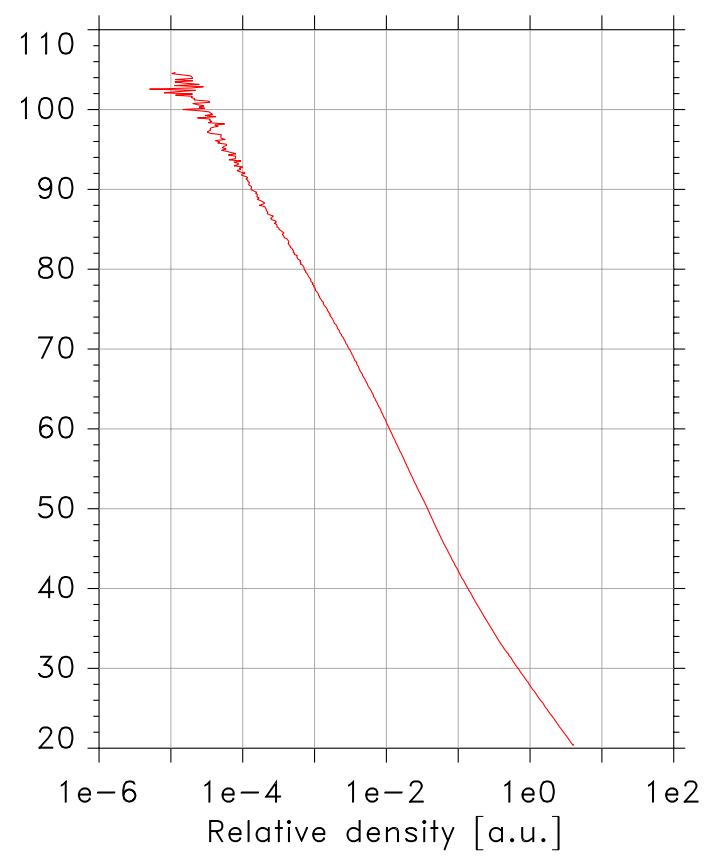

(a) Concatenated density profile

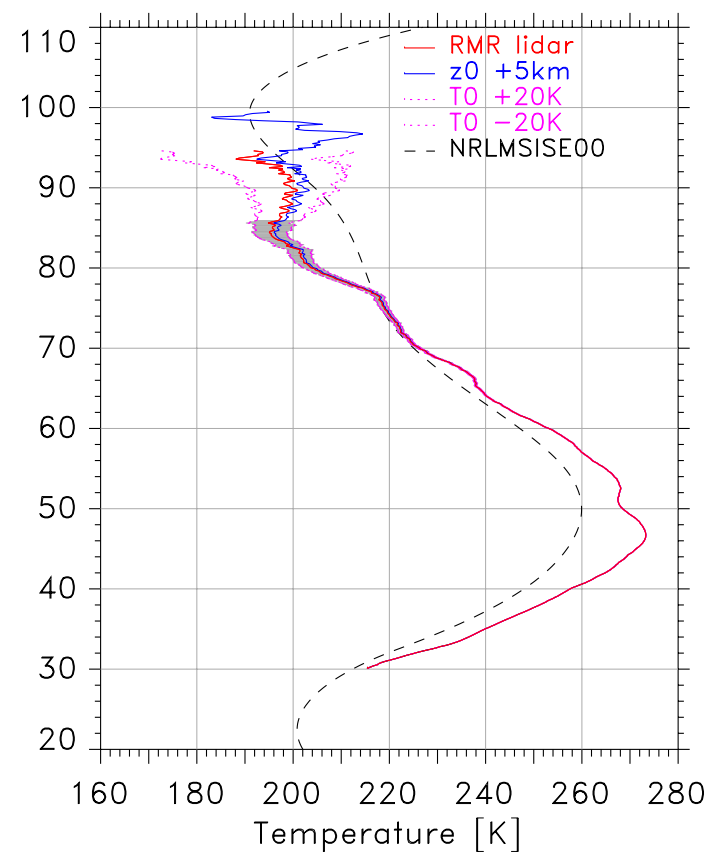

(b) Calculated temperature profile

Fig. A3. Example for the downward temperature integration as described in Sect. 3 for the measurement on 13 February 2005 17:00 UT05:00 UT. Left panel: Concatenated relative density profiles (note the exponential scale on the x-axis). Right panel: Corresponding temperature profile in red with the start temperature taken from NRLMSISE00 (black dashed line). The violet lines show the resulting temperature profiles when the start temperature is varied by $\pm 20 \mathrm{~K}$. For the blue line the temperature integration was started $5 \mathrm{~km}$ higher. The gray error bars are shown where the statistical error of the red profile drops below $5 \mathrm{~K}$.

altitude. The corresponding temperature profile is shown in the right panel of Fig. A3 (red line) together with the NRLMSISE00 reference atmosphere from which the start temperature for the integration is taken at $94.8 \mathrm{~km}$. The right panel of Fig. A3 includes two additional violet lines which were obtained by varying the start temperature by $\pm 20 \mathrm{~K}$. This is also the uncertainty assumed for the start temperature in the error propagation (see below). These lines show that the uncertainty introduced by the start temperature decreases rapidly below the start height and has virtually disappeared two scale heights below the start height. Starting the temperature integration five kilometres higher (blue line in the right panel of Fig. A3) gives a slightly different temperature profile because of the different start temperature and the noise of the relative density profile. However, the profiles agree well within the error bars. The determination of the optimal start height depends on the individual relative density profile and is described in detail in the next section. The gray error bars are shown below the height where the statistical error of the red temperature profile drops below $5 \mathrm{~K}$. All temperature profiles used in this study have been restricted to the altitude range where the statistical error is below $5 \mathrm{~K}$.
- Temperature correction in 1998: A comparison of temperature profiles calculated in 1998 from simultaneous measurements with both telescopes pointing vertically showed that there was a difference between the two telescopes due to different focusing of the telescopes with seemingly lower calculated temperatures in the North-West telescope compared to the South-East telescope. Comparisons with radiosondes showed that the South-East telescope temperatures were correct. Therefore all temperatures measured with the North-West telescope in 1998 are corrected for this offset. The temperature difference changes with height and decreases from $5 \mathrm{~K}$ at $30 \mathrm{~km}$ to $1 \mathrm{~K}$ at $90 \mathrm{~km}$. For the measurements after 1998, the focusing was checked regularly to avoid this error in the later years.

- Statistical uncertainty:

All error bars show the 1- $\sigma$ statistical uncertainty. The photon counting in the data acquisitioning of a lidar system is a Poisson process. For a raw data bin with $N$ counts, the statistical uncertainty is $\sqrt{N}$. All subsequent quantities are derived from this raw data signal and the corresponding error bars are calculated from Gaussian error propagation. Systematic errors are not represented by the error bars. 
Table B1. Middle atmosphere temperatures in K above ALOMAR from combined RMR lidar, falling sphere and ECMWF profiles (January-June). Temperatures below $30 \mathrm{~km}$ are from ECMWF at $\left(70^{\circ} \mathrm{N}, 15^{\circ} \mathrm{E}\right)$ while falling sphere data from the Andøya Rocket Range are used in the summer upper mesosphere (see Sect. 5 for details).

Height $[\mathrm{km}]$ 01.01. 11.01.21.01. 01.02.11.02.21.02. 01.03. 11.03.21.03. 01.04. 11.04. 21.04. 01.05. 11.05. 21.05. 01.06. 11.06. 21.06. $\begin{array}{lllllllllllllllllllllll}0.0 & 273.4 & 272.8 & 273.3 & 272.1 & 273.5 & 273.9 & 273.0 & 273.3 & 273.1 & 274.4 & 274.6 & 275.9 & 276.9 & 278.1 & 278.2 & 279.4 & 280.9 & 282.6 \\ 2.0 & 261.6 & 261.7 & 260.1 & 259.2 & 261.1 & 261.1 & 259.9 & 260.0 & 260.6 & 261.7 & 261.9 & 264.5 & 265.7 & 266.6 & 267.3 & 268.6 & 271.5 & 273.0 \\ 4.0 & 249.0 & 249.6 & 247.7 & 246.3 & 248.3 & 248.3 & 246.8 & 247.8 & 248.4 & 249.7 & 250.0 & 253.5 & 254.5 & 255.7 & 256.3 & 257.8 & 260.5 & 262.0 \\ 6.0 & 234.9 & 235.3 & 233.6 & 232.6 & 234.0 & 233.8 & 232.2 & 233.7 & 234.8 & 235.9 & 236.7 & 239.5 & 240.4 & 241.9 & 242.0 & 243.5 & 246.8 & 248.3 \\ 8.0 & 220.8 & 221.1 & 220.4 & 219.7 & 220.7 & 220.7 & 219.4 & 220.6 & 222.3 & 223.0 & 224.0 & 224.9 & 226.4 & 228.1 & 228.1 & 229.1 & 231.6 & 232.7 \\ 10.0 & 212.8 & 212.9 & 213.8 & 213.6 & 213.8 & 214.2 & 214.4 & 214.9 & 217.5 & 218.2 & 219.7 & 219.5 & 221.4 & 222.9 & 224.6 & 224.9 & 224.8 & 225.4 \\ 12.0 & 211.0 & 211.4 & 212.4 & 212.4 & 212.5 & 213.1 & 213.7 & 214.6 & 218.1 & 219.0 & 220.7 & 221.2 & 223.6 & 224.8 & 227.1 & 227.6 & 226.9 & 227.8 \\ 14.0 & 209.3 & 209.5 & 210.3 & 210.0 & 210.7 & 211.8 & 212.1 & 213.7 & 217.2 & 218.5 & 220.1 & 221.2 & 223.0 & 224.6 & 226.0 & 226.6 & 227.0 & 227.7 \\ 16.0 & 205.5 & 205.7 & 206.7 & 206.4 & 207.3 & 209.3 & 209.5 & 211.5 & 215.3 & 216.7 & 218.3 & 220.0 & 221.4 & 223.4 & 225.0 & 225.5 & 225.9 & 226.4 \\ 18.0 & 201.8 & 202.3 & 203.5 & 203.2 & 204.5 & 206.8 & 207.3 & 209.8 & 213.6 & 215.4 & 217.0 & 219.4 & 220.6 & 222.8 & 224.9 & 225.6 & 226.0 & 226.2\end{array}$

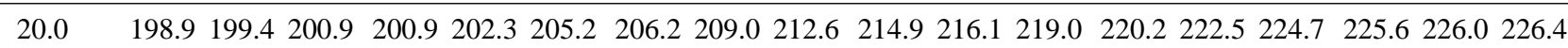
$\begin{array}{lllllllllllllllllll}22.0 & 197.2 & 197.6 & 198.9 & 199.6 & 200.9 & 204.4 & 205.9 & 208.8 & 212.1 & 214.6 & 215.8 & 218.8 & 220.4 & 222.9 & 224.9 & 225.8 & 226.4 & 226.9\end{array}$ $\begin{array}{llllllllllllllllllll}24.0 & 197.1 & 197.4 & 198.3 & 199.8 & 200.3 & 204.4 & 206.7 & 209.3 & 212.2 & 214.8 & 215.9 & 219.1 & 221.1 & 223.7 & 225.7 & 226.7 & 227.5 & 228.0\end{array}$ $\begin{array}{llllllllllllllllllll}26.0 & 194.8 & 197.8 & 197.1 & 198.8 & 197.3 & 201.8 & 206.2 & 209.3 & 211.9 & 214.6 & 215.7 & 219.0 & 222.2 & 225.0 & 226.0 & 228.1 & 229.1 & 229.8\end{array}$

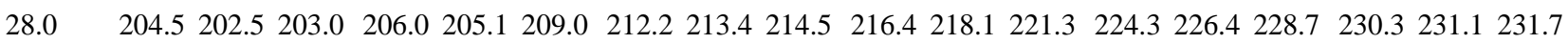

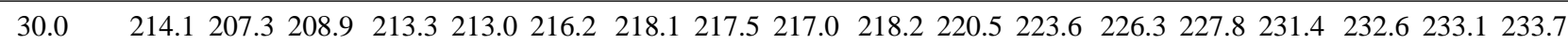
$\begin{array}{llllllllllllllllllll}32.0 & 223.7 & 212.0 & 214.9 & 220.5 & 220.8 & 223.4 & 224.1 & 221.7 & 219.6 & 220.0 & 222.9 & 225.9 & 228.4 & 229.2 & 234.1 & 234.8 & 235.0 & 235.7\end{array}$ $\begin{array}{llllllllllllllllllll}34.0 & 234.3 & 217.3 & 221.6 & 227.8 & 228.5 & 231.6 & 230.5 & 225.8 & 223.0 & 225.5 & 228.8 & 232.1 & 232.6 & 232.7 & 238.7 & 239.9 & 240.3 & 241.0\end{array}$ $\begin{array}{lllllllllllllllllll}36.0 & 245.9 & 222.5 & 227.3 & 234.6 & 235.1 & 239.1 & 235.9 & 228.8 & 226.3 & 232.3 & 235.6 & 238.8 & 238.4 & 238.7 & 243.0 & 245.2 & 246.3 & 246.5\end{array}$

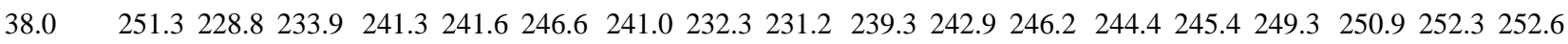

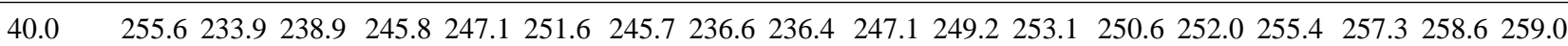
$\begin{array}{llllllllllllllllllll}42.0 & 261.1 & 239.3 & 243.3 & 249.5 & 251.3 & 255.5 & 249.8 & 242.5 & 243.3 & 253.9 & 255.1 & 260.3 & 257.2 & 258.1 & 261.7 & 263.4 & 265.0 & 265.3\end{array}$ $\begin{array}{lllllllllllllllllll}44.0 & 266.1 & 245.2 & 247.4 & 252.4 & 255.8 & 259.4 & 252.8 & 247.8 & 249.4 & 259.2 & 259.9 & 266.3 & 262.8 & 263.7 & 267.3 & 268.5 & 270.1 & 270.3\end{array}$ $\begin{array}{llllllllllllllllllll}46.0 & 266.4 & 249.1 & 250.3 & 255.3 & 261.3 & 262.8 & 255.3 & 251.9 & 254.0 & 263.7 & 264.3 & 270.2 & 268.1 & 269.1 & 271.7 & 271.6 & 274.6 & 274.6\end{array}$ $\begin{array}{llllllllllllllllllll}48.0 & 266.4 & 253.1 & 251.8 & 256.6 & 263.7 & 265.0 & 256.9 & 254.3 & 257.2 & 264.8 & 266.8 & 272.0 & 270.4 & 272.3 & 275.2 & 276.3 & 277.3 & 276.5\end{array}$

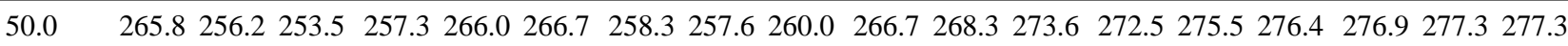
$\begin{array}{lllllllllllllllllll}52.0 & 266.1 & 258.7 & 256.0 & 257.7 & 265.1 & 265.1 & 257.8 & 257.9 & 260.9 & 267.3 & 267.3 & 272.4 & 272.4 & 274.8 & 276.3 & 276.9 & 277.5 & 278.9\end{array}$ $\begin{array}{lllllllllllllllllll}54.0 & 264.7 & 261.1 & 256.5 & 257.0 & 264.2 & 262.2 & 256.0 & 257.5 & 261.4 & 263.6 & 265.1 & 269.8 & 268.8 & 272.6 & 274.6 & 274.7 & 275.7 & 276.9\end{array}$ $\begin{array}{lllllllllllllllllll}56.0 & 261.1 & 258.2 & 253.9 & 254.3 & 262.7 & 260.3 & 255.3 & 258.5 & 261.9 & 263.0 & 262.9 & 266.1 & 266.2 & 268.8 & 272.5 & 272.4 & 272.6 & 272.9\end{array}$ $\begin{array}{lllllllllllllllllll}58.0 & 252.9 & 253.4 & 251.2 & 250.9 & 263.0 & 258.2 & 253.0 & 256.2 & 258.5 & 260.9 & 260.2 & 260.0 & 262.7 & 265.4 & 270.5 & 270.5 & 270.8 & 270.6\end{array}$

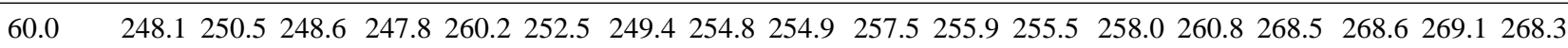

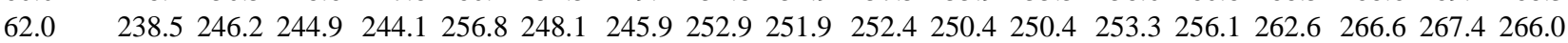

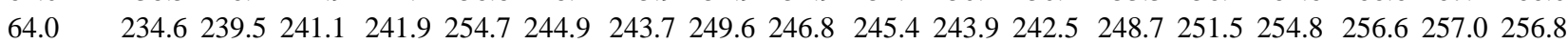
$\begin{array}{lllllllllllllllllll}66.0 & 228.6 & 235.3 & 238.7 & 238.6 & 250.9 & 240.4 & 240.8 & 246.3 & 241.6 & 237.0 & 234.3 & 236.6 & 244.0 & 246.9 & 245.8 & 247.1 & 247.5 & 247.0\end{array}$ $68.0 \quad 223.4236 .4237 .3 \quad 235.5246 .3234 .0 \quad 241.2245 .8237 .6231 .0227 .8228 .7231 .6234 .4235 .7 \quad 236.5236 .5236 .0$

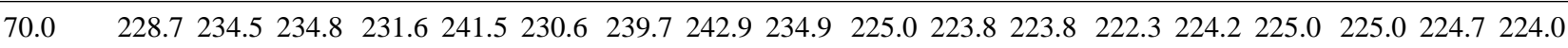
$\begin{array}{lllllllllllllllllll}72.0 & 220.2 & 234.9 & 230.2 & 228.2 & 240.7 & 229.5 & 237.2 & 240.3 & 231.5 & 219.5 & 219.7 & 219.3 & 213.5 & 213.7 & 213.5 & 212.8 & 212.2 & 211.3\end{array}$ $\begin{array}{llllllllllllllllllll}74.0 & 217.6 & 236.9 & 224.5 & 223.3 & 236.3 & 220.0 & 231.9 & 235.6 & 226.2 & 214.7 & 214.4 & 211.5 & 205.0 & 203.5 & 202.2 & 200.7 & 199.3 & 198.3\end{array}$ $\begin{array}{llllllllllllllllllll}76.0 & 215.7 & 236.9 & 219.0 & 216.7 & 227.4 & 217.0 & 225.7 & 230.7 & 219.2 & 211.5 & 208.4 & 203.7 & 197.0 & 193.5 & 190.8 & 188.4 & 186.6 & 185.3\end{array}$

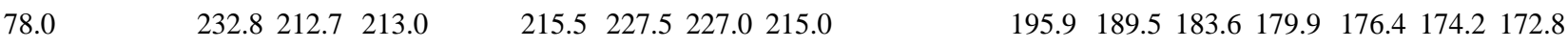

$\begin{array}{lllllllllllllllll}80.0 & 206.1 & 206.6 & 216.9 & 216.9 & 219.2 & 206.2 & 192.0 & 182.3 & 174.6 & 169.5 & 165.1 & 162.5 & 160.8\end{array}$

$\begin{array}{rrrr}82.0 & 197.0 & 199.4 & 204.6\end{array}$

$\begin{array}{lll}84.0 & 197.0 & 199.0 \\ 86.0 & 202.3\end{array}$

86.0 $\begin{array}{lllllll}187.5 & 176.0 & 166.4 & 160.0 & 154.9 & 151.8 & 150.0\end{array}$ $\begin{array}{lllllll}183.0 & 170.2 & 159.2 & 151.9 & 146.0 & 142.6 & 140.8\end{array}$ $\begin{array}{llllllll}178.3 & 165.2 & 153.3 & 145.1 & 139.0 & 135.3 & 133.0\end{array}$ $\begin{array}{lllllll}173.0 & 160.6 & 149.4 & 141.4 & 135.3 & 131.5 & 129.5\end{array}$

90.0 $\begin{array}{llllllll}167.3 & 157.0 & 148.2 & 141.8 & 137.0 & 134.2 & 133.0\end{array}$ 92.0 $\begin{array}{lllllll}160.8 & 154.1 & 150.0 & 148.0 & 146.7 & 146.8 & 146.8\end{array}$ 
Table B1. Continued (July-December).

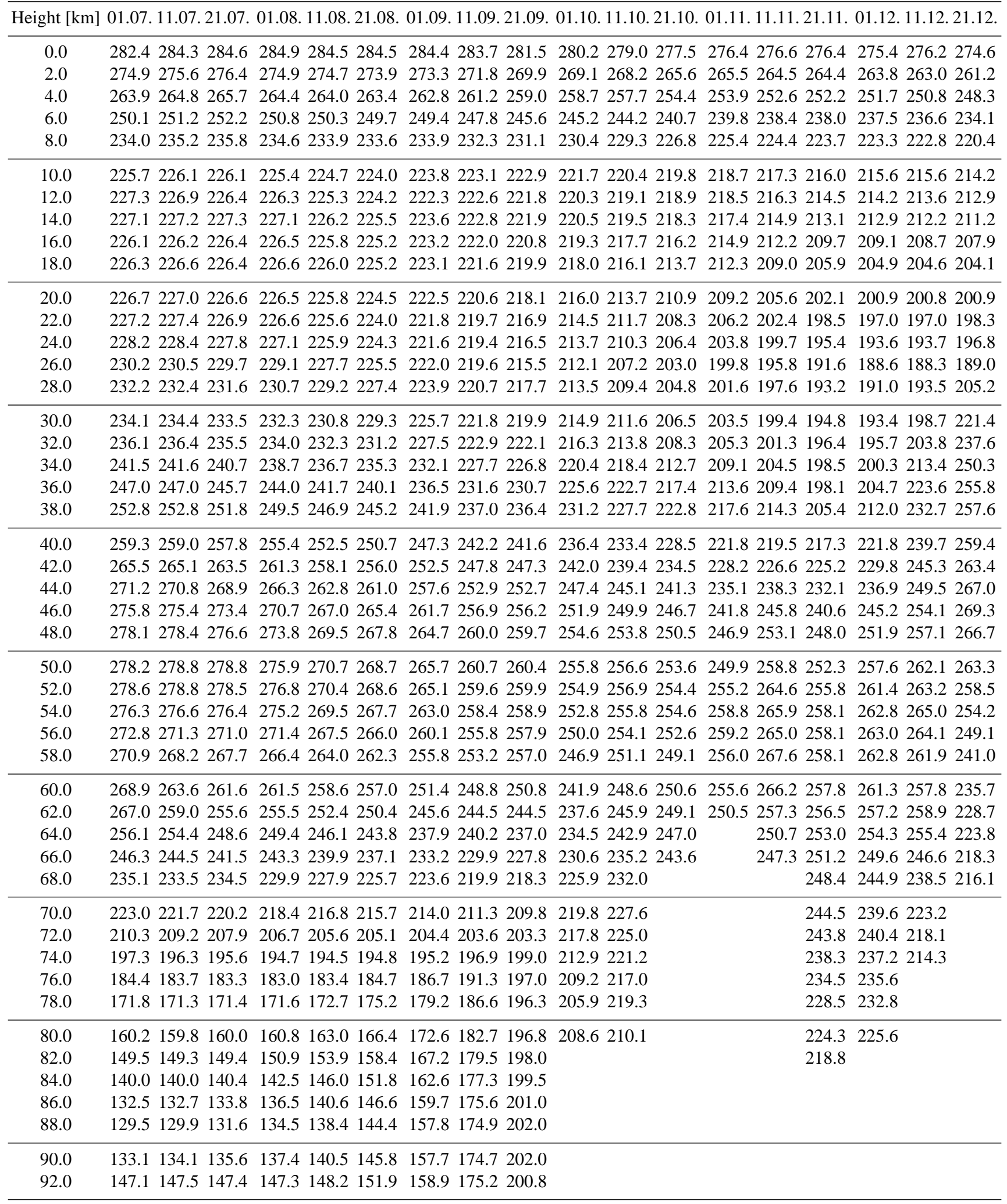


These are the steps necessary to convert the summed raw count rate profiles from the RMR lidar measurements to temperature profiles. The next section will discuss in more detail the determination of the background shape and of the start height for the temperature integration.

\section{A3 Selection of optimal start height}

For an ideal lidar instrument, the background is constant with altitude and can be determined at high altitudes where no atmospheric signal is present. For real lidar instruments however, the background is sometimes distorted and has to be approximated by a linear or parabolic fit over an altitude range without atmospheric signal rather than by a constant. One reason for a disturbed background is signal induced noise due to overloading of the detectors (Pettifer, 1975). Although the detection system is designed to avoid detector overloading, it happens occasionally, especially when the tropospheric transmission is very variable due to clouds. For the RMR lidar data processing in this study, the determination of the background shape is combined with the identification of the optimal start height for the temperature integration as described below.

Selecting the optimal start height is important because it involves a trade-off between larger altitude coverage and smaller error. An outlier value of the relative density profile forces the temperature calculation far off the true temperature. Due to the algorithm design, the calculated temperature profile will eventually return to the true temperature but this may take up to two scale heights (see right panel of Fig. A3). Therefore it is sometimes better to start a few kilometres below the upper end of the available relative density profile.

The background shape is determined either as constant, linear or parabolic fit in the altitude range from $25 \mathrm{~km}$ above the upper end of the Rayleigh signal to $250 \mathrm{~km}$. First the upper end of the Rayleigh lidar signal determined earlier is used as the start height. If the different background shapes yield strongly deviating temperature profiles, the start height is not suitable for an unambiguous determination of the true temperature and the calculation is repeated starting $2 \mathrm{~km}$ lower. Since the influence of the background shape on the relative density signal after background subtraction gets smaller with decreasing height, the differences between the temperature profiles calculated for the three background shapes decrease when the start height is lowered. The start height is therefore decreased until the assumed shape of the background does no longer lead to significant differences of the three calculated temperature profiles. The temperature profile calculated using a constant background is then identified as the most credible temperature profile.

\section{Appendix B}

\section{Tabulated temperature climatology}

The seasonal temperatures variations above ALOMAR from RMR lidar, falling spheres and ECMWF (Fig. 6) are listed as a function of altitude in Table B1 below.

Acknowledgements. The authors wish to thank the ALOMAR crew for their help and effort to operate the RMR lidar. We thank K. H. Fricke for extensive helpful comments. The European Centre for Medium-Range Weather Forecasts (ECMWF) is gratefully acknowledged for providing access to their data archive. This project received research funding from the European Community's 6th Framework Program under the project "ALOMAR eARI" (RITACT-2003-506208).

Topcial Editor U.-P. Hoppe thanks Chiao-Yao She and another anonymous referee for their help in evaluating this paper.

\section{References}

Alpers, M., Eixmann, R., Fricke-Begemann, C., Gerding, M., and Höffner, J.: Temperature lidar measurements from 1 to $105 \mathrm{~km}$ altitude using resonance, Rayleigh, and rotational Raman scattering, Atmos. Chem. Phys., 4, 793-800, 2004, http://www.atmos-chem-phys.net/4/793/2004/.

Andrews, D. G., Holton, J. R., and Leovy, C. B.: Middle atmosphere dynamics, vol. 40 of International Geophysics Series, Academic Press Inc., Orlando, USA, 1987.

Bakan, S., Hinzpeter, H., Höller, H., Jeske, H., Laube, M., Volland, H., Warneck, P., and Wurzinger, C.: Meteorology - Physical and chemical properties of the air, vol. V/4b of Landolt-Börnstein Numerical data and functional relationships in science and technology, Springer Verlag, Berlin, 1988.

Baumgarten, G., Lübken, F.-J., and Fricke, K. H.: First observation of one noctilucent cloud by a twin lidar in two different directions, Ann. Geophys., 20, 1863-1868, 2002, http://www.ann-geophys.net/20/1863/2002/.

Berger, U.: Modeling of middle atmosphere dynamics with LIMA, J. Atmos. Sol.-Terr. Phys., 20(8-9), 1170-1200, doi:10.1016/j. jastp.2008.02.004, 2008.

Blum, U.: Lidarbeobachtungen der polaren Atmosphäre: Wolken und Wellen - Phänomene und Mechanismen, Ph.D. thesis, Universität Bonn, Bonn, Germany, 2003.

Blum, U. and Fricke, K. H.: The Bonn University lidar at the Esrange: Technical description and capabilities for atmospheric research, Ann. Geophys., 23, 1645-1658, 2005, http://www.ann-geophys.net/23/1645/2005/.

Blum, U. and Fricke, K. H.: Indications for a long-term temperature change in the polar summer middle atmosphere, J. Atmos. Sol.Terr. Phys., 70, 123-137, doi:10.1016/j.jastp.2007.09.015, 2008.

Burrows, J. P., Richter, A., Dehn, A., Deters, B., Himmelmann, S., Voigt, S., and Orphal, J.: Atmospheric remote-sensing reference data from GOME2. Temperature-dependent absorption cross sections of $\mathrm{O}_{3}$ in the $231-794 \mathrm{~nm}$ range, J. Quant. Spectrosc. Ra., 61, 509-517, doi:10.1016/S0022-4073(98)00037-5, 1999.

Di Girolamo, P., Cacciani, M., di Sarra, A., Fiocco, G., and Fuà, D.: Lidar observations of the Pinatubo aerosol layer at 
Thule, Greenland, Geophys. Res. Lett., 21, 1295-1298, doi: 10.1029/93GL02892, 1994.

Duck, T. J., Whiteway, J. A., and Carswell, A. I.: A detailed record of High Arctic middle atmospheric temperatures, J. Geophys. Res., 105, 22 909-22 918, doi:10.1029/2000JD900367, 2000.

Fiedler, J. and von Cossart, G.: Automated lidar transmitter for multiparameter investigations within the Arctic atmosphere, IEEE T. Geosci. Remote, 37, 748-755, doi:10.1109/36.752191, 1999.

Fiedler, J., von Cossart, G., and von Zahn, U.: Stratospheric/Mesospheric temperature profiles obtained by the ALOMAR RMR-lidar over Andøya, in: Proceedings of the 14th ESA Symposium on European Rocket and Balloon Programmes and Related Research, edited by: Kaldeich-Schürmann, B., vol. ESA SP-437, pp. 263-268, Potsdam, Germany, 1999.

Fiedler, J., von Cossart, G., and Baumgarten, G.: Noctilucent clouds above ALOMAR between 1997 and 2001: Occurrence and properties, J. Geophys. Res., 108, 8453, doi:10.1029/2002JD002419, 2003.

Fierli, F., Hauchecorne, A., Nedeljkovic, D., Mehrtens, H., von Zahn, U., and Fricke, K. H.: Relationship between PSC events and temperature measured by ALOMAR RMR lidar at Andøya $\left(69^{\circ} \mathrm{N}, 16^{\circ} \mathrm{E}\right)$, in: Atmospheric Ozone: Proceedings of the XVII Quadrennial Ozone Symposium, edited by: Bojkov, R. D. and Visconti, G., pp. 503-506, L'Aquila, Italy, 1998.

Fleming, E. L., Chandra, S., Barnett, J. J., and Corney, M.: Zonal mean temperature, pressure, zonal wind, and geopotential height as functions of latitude, COSPAR international reference atmosphere: 1986, Part II: Middle atmosphere models, Adv. Space Res., 10, 11-59, doi:10.1016/0273-1177(90)90386-E, 1990.

Fortuin, J. P. F. and Langematz, U.: An update on the global ozone climatology and on concurrent ozone and temperature trends, in: Proceedings of the SPIE symposium "Atmospheric sensing and modelling", edited by: Santer, R. P., 2311, 207-216, SPIE, Bellingham, WA, Rome, Italy, doi:10.1117/12.198578, 1995.

Fricke, K. H. and von Zahn, U.: Mesopause temperatures derived from probing the hyperfine structure of the $\mathrm{D}_{2}$ resonance line of sodium by lidar, J. Atmos. Terr. Phys., 47, 499-512, doi:10.1016/ 0021-9169(85)90116-3, 1985.

Hauchecorne, A. and Chanin, M. L.: Density and temperature profiles obtained by lidar between 35 and $70 \mathrm{~km}$, Geophys. Res. Lett., 7, 565-568, 1980.

Hübner, F.: Temperaturen der mittleren polaren Atmosphäre $(15-80 \mathrm{~km})$ : Beobachtungen mit dem ALOMAR Rayleigh/Mie/Raman-Lidar 1995 und 1996 und Vergleiche, Ph.D. thesis, Universität Rostock, Rostock, Germany, available from "http://www.iap-kborn.de/Thesis-Master-Diploma-PhD. 64.0.html?\&L=1", 1998.

Junge, C. E., Chagnon, C. W., and Manson, J. E.: Stratospheric aerosols, J. Meteor., 18, 81-108, doi:10.1175/1520-0469(1961) 018<0081:SA $\rangle$ 2.0.CO;2, 1961.

Keckhut, P., Hauchecorne, A., and Chanin, M. L.: A critical review of the database acquired for the long-term surveillance of the middle atmosphere by the French Rayleigh lidars, J. Atmos. Ocean. Technol., 10, 850-867, doi:10.1175/1520-0426(1993) 010<0850:ACROTD $>2.0 . C O ; 2,1993$.

Kent, G. S. and Wright, R. W. H.: A review of laser radar measurements of atmospheric properties, J. Atmos. Terr. Phys., 32, 917-943, doi:10.1016/0021-9169(70)90036-X, 1970.

Kurzawa, H. and von Zahn, U.: Sodium density and atmospheric temperature in the mesopause region in polar summer, J. Atmos. Terr. Phys., 52, 981-993, doi:10.1016/0021-9169(90)90029-M, 1990.

Lübken, F.-J.: Thermal structure of the Arctic summer mesosphere, J. Geophys. Res., 104, 9135-9149, doi:10.1029/1999JD900076, 1999.

Lübken, F.-J. and von Zahn, U.: Thermal structure of the mesopause region at polar latitudes, J. Geophys. Res., 96, 20 841-20 857, 1991.

Martin, W. E. and Winfield, R. J.: Nonlinear effects on pulsed laser propagation in the atmosphere, Appl. Optics, 27, 567-577, 1988.

McGee, T. J., Gross, M., Newman, P., Beyerle, G., Beninga, I., Dahl, A., Neuber, R., Wahl, P., and Schrems, O.: Lidar temperature measurements at $\mathrm{Ny}$-Ålesund $(79 \mathrm{~N})$ during winter, 1998, in: Proceedings of the $19^{t h}$ International Laser Radar Conference, edited by: Singh, U. N., Ismail, S., and Schwemmer, G. K., vol. NASA no. 19980227658 , pp. 343-346, Annapolis, MD, USA, 1998.

Müllemann, A.: Temperaturen, Winde und Turbulenz in der polaren Sommermesosphäre, Ph.D. thesis, Universität Rostock, Rostock, Germany, available from "http://www.iap-kborn.de/ Thesis-Master-Diploma-PhD.64.0.html?\&L=1”, 2004.

Neuber, R., von der Gathen, P., and von Zahn, U.: Altitude and temperature of the mesopause at $69^{\circ} \mathrm{N}$ latitude in winter, J. Geophys. Res., 93, 11 093-11 101, 1988.

Pan, W. and Gardner, C. S.: Seasonal variations of the atmospheric temperature structure at South Pole, J. Geophys. Res., 108, 4564 doi:10.1029/2002JD003217, 2003.

Pettifer, R. E. W.: Signal induced noise in lidar experiments, J. Atmos. Terr. Phys., 37, 669-673, doi:10.1016/0021-9169(75) 90062-8, 1975.

Picone, J. M., Hedin, A. E., Drob, D. P., and Aikin, A. C.: NRLMSISE-00 empirical model of the atmosphere: Statistical comparison and scientific issues, J. Geophys. Res., 107, 1468, doi:10.1029/2002JA009430, 2002

Rees, D., von Zahn, U., von Cossart, G., Fricke, K. H., Eriksen, W., and McKay, J. A.: Daytime lidar measurements of the stratosphere and mesosphere at the ALOMAR observatory, Adv. Space Res., 26, 893-902, doi:10.1016/S0273-1177(00)00027-2, 2000.

Schöch, A.: Thermal structure and gravity waves in the Arctic middle atmosphere above ALOMAR $\left(69.3^{\circ} \mathrm{N}, 16.0^{\circ} \mathrm{E}\right)$, Ph.D. thesis, Universität Rostock, Rostock, Germany, available from "http://www.iap-kborn.de/Thesis-Master-Diploma-PhD.64.0. html?\&L=1", 2007

Schöch, A. and Baumgarten, G.: A new system for automatic beam stabilisation of the ALOMAR RMR-lidar at Andøya in Northern Norway, in: Proceedings of the 16th ESA Symposium on European Rocket and Balloon Programmes and Related Research, edited by: Warmbein, B., vol. ESA SP-530, pp. 303-307, St. Gallen, Switzerland, 2003.

Schöch, A., Baumgarten, G., Fritts, D. C., Hoffmann, P., Serafimovich, A., Wang, L., Dalin, P., Müllemann, A., and Schmidlin, F. J.: Gravity waves in the troposphere and stratosphere during the MaCWAVE/MIDAS summer rocket program, Geophys. Res. Lett., 31, L24S04, doi:10.1029/2004GL019837, 2004.

She, C.-Y., Vance, J. D., Williams, B. P., Krueger, D. A., Moosmüller, H., Gibson-Wilde, D., and Fritts, D. C.: Lidar studies of atmospheric dynamics near polar mesopause, Trans. Am. Geophys. Union (EOS), 83, 289-293, doi:10.1029/ 
2002EO000206, 2002.

Thayer, J. P., Nielsen, N. B., Warren, R. E., Heinselmann, C. J., and Sohn, J.: Rayleigh lidar system for middle atmosphere research in the Arctic, Opt. Eng., 36, 2045-2061, 1997.

Theon, J. S., Nordberg, W., Katchen, L. B., and Horvath, J. J.: Some observations on the thermal behaviour of the mesosphere, J. Atmos. Sci., 24, 428-438, doi:10.1175/1520-0469(1967) 024〈0428:SOOTTB $\rangle$ 2.0.CO;2, 1967.

Thomas, G. E., Olivero, J. J., Jensen, E. J., Schröder, W., and Toon, O. B.: Relation between increasing methane and the presence of ice clouds at the mesopause, Nature, 338, 490-492, doi:10.1038/ 338490a0, 1989.

Thulasirama, S. and Nee, J. B.: Further evidence of a twolevel mesopause and its variations from UARS high-resolution Doppler imager temperature data, J. Geophys. Res., 107, 4355, doi:10.1029/2000JD000118, 2002.

von Cossart, G., Fiedler, J., von Zahn, U., Fricke, K. H., Nußbaumer, V., Nelke, G., Hübner, F., Hauchecorne, A., Marcovici, J. P., Fassina, F., Nedeljkovic, D., Rees, D., and Meredith, N. P.: Modern technologies employed in the ALOMAR Rayleigh/Mie/Raman lidar, in: Proceedings of the 12th ESA Symposium on European Rocket and Balloon Programmes and Related Research, edited by: Blix, T. A., vol. ESA SP-370, pp. 387-394, Lillehammer, Norway, 1995. von Zahn, U.: Are noctilucent clouds truly a "miner's canary" for global change?, Trans. Am. Geophys. Union (EOS), 84, 261264, doi:10.1029/2003EO280001, 2003.

von Zahn, U. and Meyer, W.: Mesopause temperatures in summer, J. Geophys. Res., 94, 14 647-14 651, 1989.

von Zahn, U. and Neuber, R.: Thermal structure of the high latitude mesopause region in winter, Contributions to Atmospheric Physics, 60, 294-304, 1987.

von Zahn, U., Fiedler, J., Naujokat, B., Langematz, U., and Krüger, K.: A note on record-high temperatures at the northern polar stratopause in winter 1997/98, Geophys. Res. Lett., 25, 41694172, doi:10.1029/1998GL900091, 1998.

von Zahn, U., von Cossart, G., Fiedler, J., Fricke, K. H., Nelke, G., Baumgarten, G., Rees, D., Hauchecorne, A., and Adolfsen, K.: The ALOMAR Rayleigh/Mie/Raman lidar: Objectives, configuration, and performance, Ann. Geophys., 18, 815-833, 2000, http://www.ann-geophys.net/18/815/2000/.

Whiteway, J. A. and Carswell, A. I.: Rayleigh lidar observations of thermal structure and gravity wave activity in the high Arctic during a stratospheric warming, J. Atmos. Sci., 51, 3122-3136, doi: 10.1175/1520-0469(1994)051〈3122:RLOOTS〉2.0.CO;2, 1994. 